University of Nebraska - Lincoln

DigitalCommons@University of Nebraska - Lincoln

Finance Department Faculty Publications

Finance Department

$9-2005$

\title{
Quantifying Cognitive Biases in Analyst Earnings Forecasts
}

Geoffrey C. Friesen

University of Nebraska-Lincoln, gfriesen2@unl.edu

Paul Weller

University of lowa, Paul-Weller@uiowa.edu

Follow this and additional works at: https://digitalcommons.unl.edu/financefacpub

Part of the Finance and Financial Management Commons

Friesen, Geoffrey C. and Weller, Paul, "Quantifying Cognitive Biases in Analyst Earnings Forecasts" (2005). Finance Department Faculty Publications. 23.

https://digitalcommons.unl.edu/financefacpub/23

This Article is brought to you for free and open access by the Finance Department at DigitalCommons@University of Nebraska - Lincoln. It has been accepted for inclusion in Finance Department Faculty Publications by an authorized administrator of DigitalCommons@University of Nebraska - Lincoln. 


\title{
Quantifying Cognitive Biases in Analyst Earnings Forecasts
}

\author{
Geoffrey Friesen* \\ University of Nebraska-Lincoln \\ gfriesen2@unl.edu \\ Paul A. Weller** \\ University of Iowa \\ paul-weller@uiowa.edu
}

\section{September 2005}

* Department of Finance, University Of Nebraska-Lincoln, 237 CBA, Lincoln, NE 68588-0490. Tel: 402.472.2334. Fax: 402.472.5140 ** Department of Finance, Henry B. Tippie College of Business, University of Iowa, Iowa City, IA 522421000. Tel: 319.335.1017. Fax: 319.335.3690. We would like to thank Gene Savin, Matt Billett, Anand Vijh, Ashish Tiwari, Gary Koppenhaver, Jim Schmidt and seminar participants at the University of Iowa, University of Nebraska-Lincoln, Iowa State University, Northern Illinois, SUNY at Albany and the 2003 FMA Annual Meeting for helpful comments. We are grateful to I/B/E/S International Inc. for providing the earnings forecast data under their Academic Research Program. 


\title{
Quantifying Cognitive Biases in Analyst Earnings Forecasts
}

\begin{abstract}
This paper develops a formal model of analyst earnings forecasts that discriminates between rational behavior and that induced by cognitive biases. In the model, analysts are Bayesians who issue sequential forecasts that combine new information with the information contained in past forecasts. The model enables us to test for cognitive biases, and to quantify their magnitude. We estimate the model and find strong evidence that analysts are overconfident about the precision of their own information and also subject to cognitive dissonance bias. But they are able to make corrections for bias in the forecasts of others. We show that our measure of overconfidence varies with book-to-market ratio in a way consistent with the findings of Daniel and Titman (1999). We also demonstrate the existence of these biases in international data.
\end{abstract}




\section{Quantifying Cognitive Biases in Analyst Earnings Forecasts}

\section{Introduction}

Earnings forecasts are an important source of information for security valuation. Almost all valuation models use such forecasts explicitly or implicitly as an input in some way or another. Analyst forecasts have been shown to be more accurate than univariate time series or other naïve forecast methods (Brown and Rozeff, 1978; Fried and Givoly, 1982; Brown et al., 1987) and to have economic value for investors (Givoly and Lakonishok, 1984). But many investigators have found that the forecasts are biased (overly optimistic) (for example Stickel 1990, Abarbanell 1991, Brown, 1997; Easterwood and Nutt 1999) and inefficient in the way that they incorporate new information (DeBondt and Thaler, 1990; Abarbanell, 1991; LaPorta, 1996; Zitzewitz, 2001a). Our focus in this paper is explicitly on the latter source of bias. Our aim is to throw further light on the nature of the inefficiency and on its economic significance.

More specifically, we present evidence relevant for assessing recent asset pricing models that have relaxed the assumption of full rationality in order to provide explanations for certain persistent features of the data that are not adequately explained by the standard theory (Daniel, Hirshleifer and Subrahmanyam, 1998, 2001; Odean, 1998; Barberis, Shleifer and Vishny, 1998). Daniel, Hirshleifer and Subrahmanyam (1998) develop a behavioral model based on the assumption that investors display overconfidence and self-attribution bias with respect to their private information about stock returns. Overconfidence causes them to attach excessive weight to private relative to public information. Self-attribution bias refers to the tendency to attribute success to skill and failure to misfortune and accentuates the effect of overconfidence in the short run. The model generates asset prices that display short-horizon momentum and long-horizon mean reversion. It also predicts that the magnitude of the short-horizon momentum effect will depend upon the severity of the investor's overconfidence and self-attribution bias.

If investors are overconfident in their assessment of private information, then we would expect to observe similar biases in the way that security analysts process information to produce earnings forecasts. Our model of security analyst earnings forecasts contrasts rational and biased forecasts. In addition to overconfidence we consider another bias extensively documented in the psychology literature, that of cognitive dissonance. An individual who is overconfident overestimates the precision of his private information. Cognitive dissonance can be characterized 
by the proposition that individuals tend to acquire or perceive information to conform with a set of desired beliefs. ${ }^{1}$ Thus if an analyst issues an optimistic earnings forecast on the basis of favorable private information, she will have a tendency to interpret subsequent information in such a way as to support or conform to the prior belief. ${ }^{2}$ We develop a series of tests that identify and measure both the information content and cognitive biases in earnings forecasts. Notably, both of these measures are independent of asset prices and the momentum effect. ${ }^{3}$ Using data on individual analyst forecasts, we estimate the model and find strong evidence of both overconfidence and cognitive dissonance in analyst earnings forecasts.

\section{An Empirical Measure of Forecast Inefficiency}

To provide some initial motivation we consider a simple atheoretic approach to measuring forecast inefficiency. A fundamental property of an optimal forecast is that it is not possible to improve the accuracy of the forecast by conditioning on any information available at the time the forecast is made. In particular, if we observe a sequence of earnings forecasts, then we should not be able to increase the precision of the $\mathrm{i}^{\text {th }}$ forecast by conditioning on earlier forecasts.

We examine this question by comparing the precision of the $i^{\text {th }}$ quarterly earnings forecast with that of forecasts conditioned also on earlier forecasts. If analyst forecasts are efficient, then the $\mathrm{i}^{\text {th }}$ forecast $F_{t, t-1}^{i}$ will be the optimal predictor of actual time $t$ earnings, $A_{t}$. In particular, the $\mathrm{i}^{\text {th }}$ forecast $F_{t, t-1}^{i}$ will efficiently combine information from past forecasts $\left.F_{t, t-1}^{j}\right|_{j=1} ^{i-1}$, as well as the $\mathrm{i}^{\text {th }}$ analyst's own private information. The precision of the $\mathrm{i}^{\text {th }}$ forecast will therefore exceed the precision obtainable by mechanically combining past forecasts, $\left.F_{t, t-1}^{j}\right|_{j=1} ^{i-1}$. Also, since the $\mathrm{i}^{\text {th }}$ forecast optimally combines past forecasts and the $\mathrm{i}^{\text {th }}$ analyst's own private information, it will not be possible to improve upon the $i^{\text {th }}$ forecast by mechanically combining the $\mathrm{i}^{\text {th }}$ forecast with past forecasts.

We look at the precision of three forecasting variables, where precision is defined as the inverse mean squared forecast error (Greene, 1997). ${ }^{4}$ The first forecasting variable, labeled $F V_{t, t-1}^{1}$, is simply the $\mathrm{i}^{\text {th }}$ analyst's forecast of time $t$ earnings, $F_{t, t-1}^{i}$. The second forecasting variable, labeled $F V_{t, t-1}^{2}$, is a predictor of time t earnings obtained by regressing time t earnings 
on lagged forecasts $\left.F_{t, t-1}^{j}\right|_{j=1} ^{i-1}$, all of which are observable when the $\mathrm{i}^{\text {th }}$ analyst issues her forecast $F_{t, t-1}^{i}$. The third variable, labeled $F V_{t, t-1}^{3}$, is a predictor of time t earnings obtained by regressing time $t$ earnings on lagged forecasts and the $i^{\text {th }}$ analyst's forecast. Forecasting parameters for $F V_{t, t-1}^{2}$ and $F V_{t, t-1}^{3}$ are re-estimated each quarter, using all earnings data from previous quarters.

The precisions are plotted sequentially by forecast order in Figure 1. The figure demonstrates that the $i^{\text {th }}$ analyst's forecast precision is lower than the forecast precision obtainable by either mechanical forecasting method. Figure 2 plots the percentage difference between $F V_{t, t-1}^{1}$ (the $\mathrm{i}^{\text {th }}$ analyst's forecast) and $F V_{t, t-1}^{3}$ (which recombines the $\mathrm{i}^{\text {th }}$ analyst's forecast and past forecasts). The magnitude of the loss of accuracy in the forecast is large, ranging from around $10 \%$ for early forecasts to over $20 \%$ for late forecasts. The models developed in Sections III and IV provide an explanation for the observed inefficiency in terms of cognitive biases.

\section{Related Literature}

\section{A. Optimistic Forecast Bias}

Some research suggests that analyst forecasts exhibit an optimistic bias. That is, the average analyst earnings forecast exceeds actual earnings (Stickel 1990, Abarbanell 1991, Easterwood and Nutt 1999). The apparent optimistic bias may be due to incentive conflicts, ${ }^{5}$ may be rational, ${ }^{6}$ or may simply reflect measurement error. ${ }^{7}$ The bias has been identified in consensus forecasts (Lim 2001) and is more pronounced at longer forecast horizons (e.g. one year) than at shorter horizons (e.g. one month) (Richardson et al. 1999). We find evidence of an optimistic bias consistent with previous work but our primary focus is on biases of over- or underreaction.

\section{B. Inefficient Use of Information}

The second set of biases involves over- and underreaction to information. That is, when analysts incorporate new information into their forecasts, the new information does not receive the rational Bayesian weight. This phenomenon may be due to cognitive biases or incentive conflicts. 
Several theoretical papers have focused explicitly on the effects of performance-based incentives on analyst forecast behavior. Predictions tend to be sensitive to the assumptions of the model. Trueman (1994) finds that analysts will display a tendency to "herd" on the consensus, underweighting their own information. Other papers identify different circumstances under which one would observe either herding or exaggeration (Ehrbeck and Waldmann, 1996; Ottaviani and Sorensen, 2001).

Empirical evidence is also mixed. Lamont (1995) and Hong, Kubik and Solomon (2000) find a relationship between job tenure and herding among forecasters, in which the less experienced are more likely to follow the herd. Graham (1999) in contrast examines asset allocation recommendations of investment newsletters and finds evidence that the incentive to herd increases with analyst reputation. Zitzewitz (2001a) argues that analysts systematically exaggerate their difference from the consensus.

A number of studies have also suggested that cognitive biases cause analysts to deviate from rational Bayesian updating. DeBondt and Thaler (1990) argue that analysts tend to overreact and form extreme expectations. Others find that current analyst forecasts are predictable from past stock returns (Klein 1990) or past analyst forecast errors (Mendenhall 1991, Abarbanell and Bernard 1992), and suggest that analysts tend to underreact to new information. Easterwood and Nutt (1999) and Chen and Jiang (2005) find that analysts overreact to positive news but underreact to negative news, thus appearing systematically overoptimistic. Shane and Brous (2001) find evidence of correlation between forecast revisions and both prior forecast errors and prior forecast revisions, and conclude that analysts use non-earnings information to correct prior underreaction to information about future earnings. This diversity of findings has not gone unnoticed by advocates of market efficiency. Fama (1998, p. 306) surveys the anomalies literature and argues that "in an efficient market, apparent underreaction will be about as frequent as overreaction. If anomalies are split randomly between underreaction and overreaction, they are consistent with market efficiency."

We choose to focus solely on the task of discriminating between rational forecasting behavior and that influenced by cognitive biases. However, we recognize that in certain circumstances the incentives to exaggerate private information or herd with the consensus may be difficult to distinguish from such cognitive biases since they induce analysts to report 
forecasts which differ from their true expectations. We return to consider alternative explanations for our empirical findings in Section V.

\section{The Rational Model}

Analyst forecasts represent combinations of various pieces of public and private information. In this paper, we think of private information as encompassing traditional forms of private information (e.g. proprietary research) as well as the skillful interpretation of publicly available information. After time $t-1$ earnings are announced, analysts sequentially issue onequarter-ahead forecasts of time $t$ earnings $A_{t}$. To capture public information about $A_{t}$ available at time t-1, we introduce a statistical forecast of $A_{t}$ which we denote $\hat{A}_{t, t-1}$ :

$$
\hat{A}_{t, t-1}=E\left(A_{t} \mid I_{t-1}^{\text {public }}\right)
$$

Here, $I_{t-1}^{\text {public }}$ contains any public information known to be able to forecast earnings, which of course includes lagged earnings. We model the sequential nature of forecasts by assuming that each analyst observes her own private signal as well as all forecasts previously issued. ${ }^{8}$ The earnings innovation conditional on the public information used to generate the forecast $\hat{A}_{t, t-1}$ is denoted $\varepsilon_{t}$. Thus

$$
A_{t}=\hat{A}_{t, t-1}+\varepsilon_{t}
$$

and $\varepsilon_{t}$, which can also be interpreted as a forecast error, is uncorrelated with $\hat{A}_{t, t-1}$. We assume that $\varepsilon_{t}$ is normally distributed with mean zero and variance $\sigma_{\varepsilon}^{2}$. Then each analyst's private information is represented by a signal about $\varepsilon_{t}$. Let

$$
S_{t, t-1}^{i}=\varepsilon_{t}+\eta_{t-1}^{i}
$$

represent the $i^{\text {th }}$ private signal in order observed by the $i^{\text {th }}$ analyst. The signal is observed at some point during period $t-1$, and provides information about the innovation $\varepsilon_{t}$. We assume that $\eta_{t-1}^{i}$ is normally distributed with mean zero and variance $\left(\sigma_{\eta}^{i}\right)^{2}$, and is uncorrelated with $\varepsilon_{t}$ and with $\eta_{t-1}^{j}, j \neq i$. This particular form for the signal is a convenient way of capturing the fact that $S_{t, t-1}^{i}$ and $\varepsilon_{t}$ are correlated random variables, as of course must be true of any informative signal. It does not imply that $\varepsilon_{t}$ has been realized at time $t-1$. 
We also assume that $\sigma_{\eta}^{i}$ is public information, thus abstracting from the possibility that there may exist an incentive to provide an informative signal about $\sigma_{\eta}^{i}$ as a measure of skill. ${ }^{9}$ In models where $\sigma_{\eta}^{i}$ is not public information, optimal forecasts may deviate from the rational forecast as we define it (see for example Trueman 1994; Ehrbeck and Waldmann 1996). One may then want to think of what we call the rational model as the unbiased model. In Section V we consider the possibility that our results represent rational incentive-driven behavior.

The $i^{\text {th }}$ analyst, having observed all previous forecasts, now updates her prior in the light of her private signal. Her Bayesian forecast of earnings at time $t$ issued during period $t-1$ is denoted $F_{t, t-1}^{i}$. It is convenient at this point to introduce the notation $\pi_{\eta}^{i} \equiv 1 /\left(\sigma_{\eta}^{i}\right)^{2}$ for the precision of the $i^{\text {th }}$ private signal, and $\pi_{\varepsilon} \equiv 1 / \sigma_{\varepsilon}^{2}$ for the precision of the earnings innovation $\varepsilon_{t}$. Here, we assume that the analyst's loss function is such that the rational forecast equals the analyst's posterior expectation. ${ }^{10}$

Introducing the notation

$$
w_{i}=\frac{\pi_{\eta}^{i}}{\pi_{\varepsilon}+\sum_{j=1}^{i} \pi_{\eta}^{j}}
$$

forecasts of earnings changes can be expressed in the following way (see Appendix A.1):

$$
\begin{aligned}
& F_{t, t-1}^{1}-A_{t-1}=\left(1-w_{1}\right)\left(\hat{A}_{t, t-1}-A_{t-1}\right)+w_{1} S_{t, t-1}^{1} \\
& F_{t, t-1}^{i}-A_{t-1}=\left(1-w_{i}\right)\left(F_{t, t-1}^{i-1}-A_{t-1}\right)+w_{i} S_{t, t-1}^{i} \quad i=2, \ldots
\end{aligned}
$$

This has a straightforward interpretation. Bayesian forecasts can be expressed as weighted averages of prior mean and observed signal. In a world in which all analysts make rational forecasts, private information is correctly incorporated into each forecast. Thus each analyst will treat the immediately preceding forecast as her prior mean and earlier forecasts will have no independent effect on the current forecast. Even though signals are private information, it is sufficient that only the forecasts are observable for all information to be efficiently incorporated into successive forecasts.

Substituting for $S_{t, t-1}^{i}$ we can rewrite (5) as:

$$
F_{t, t-1}^{1}=\left(1-w_{1}\right) \hat{A}_{t, t-1}+w_{1} A_{t}+w_{1} \eta_{t-1}^{1}
$$




$$
F_{t, t-1}^{i}=\left(1-w_{i}\right) F_{t, t-1}^{i-1}+w_{i} A_{t}+w_{i} \eta_{t-1}^{i} \quad i=2, \ldots
$$

These equations relate successive forecasts to realized earnings and place strong restrictions on the various coefficients, both within and across equations. The variances of the error terms $w_{i} \eta_{t-1}^{i}$ are constrained both because of the appearance of the coefficient $w_{i}$ as a multiplicative factor and because $w_{i}$ is a nonlinear function of the variances of all preceding private signal error terms. Note that the error term in (6) is uncorrelated with all right-hand-side independent variables. It is therefore a well-defined regression equation despite the unconventional appearance of the forecasted variable $A_{t}$ on the right-hand-side. Moreover, the error term represents the individual analyst's surprise after controlling for information contained in all previous forecasts. Thus, the error terms should not exhibit the serial correlation documented in Keane and Runkle (1998).

Since the weight $w_{i}$ is a function of signal precisions, which can be estimated from the variances of the error terms in (6), the rational model imposes restrictions on parameter estimates that allow us to test it against an alternative model with cognitive biases, which we describe in the next section.

\section{The Model with Cognitive Biases}

A. The model with overconfidence

We retain the same basic structure laid out in Section III of the paper. Analysts observe previous forecasts and combine them with their own private information to produce their own forecasts. However we now assume that analyst $i$ either over- or underestimates the precision of her own private signal. The analyst perceives her private signal precision to be $\left(1+a_{i}\right) \pi_{\eta}^{i}$ where $a_{i}$ measures the degree of bias. If $a_{i}>0$ the analyst overestimates the precision of the signal, and if $a_{i}<0$ she underestimates it. We describe these situations respectively as overconfidence and underconfidence, as in Daniel, Hirshleifer and Subrahmanyam (1998). The first analyst issues a forecast which misweights the first private signal,

$$
F_{t, t-1}^{B, 1}-\hat{A}_{t, t-1}=\frac{\left(1+a_{1}\right) \pi_{\eta}^{1}}{\pi_{\varepsilon}+\left(1+a_{1}\right) \pi_{\eta}^{1}}\left(A_{t}-\hat{A}_{t, t-1}\right)+\frac{\left(1+a_{1}\right) \pi_{\eta}^{1}}{\pi_{\varepsilon}+\left(1+a_{1}\right) \pi_{\eta}^{1}} \eta_{t-1}^{1}
$$

where the superscript $B$ on the forecast stands for "biased". 


\section{Defining}

$$
w_{1}^{B}=\frac{\left(1+a_{1}\right) \pi_{\eta}^{1}}{\pi_{\varepsilon}+\left(1+a_{1}\right) \pi_{\eta}^{1}}
$$

we can rewrite (7) as:

$$
F_{t, t-1}^{B, 1}-\hat{A}_{t, t-1}=w_{1}^{B}\left(A_{t}-\hat{A}_{t, t-1}\right)+w_{1}^{B} \eta_{t-1}^{1}
$$

To describe how subsequent forecasts are made we need an assumption about whether analysts recognize the presence of bias in others. We consider the implications of the two possibilities.

If analysts are unaware of the presence of bias in others they will treat previous forecasts as fully rational. We have shown in the previous section that this implies that analysts will form forecasts as weighted averages of the immediately preceding forecast change and the private signal, as in (5).

$$
F_{t, t-1}^{B, i}-\hat{A}_{t, t-1}=\left(1-w_{i}^{B}\right)\left(F_{t, t-1}^{B, i-1}-\hat{A}_{t, t-1}\right)+w_{i}^{B} S_{t, t-1}^{i}
$$

In this situation the natural way to specify the "rational" weight is to base it on the empirical precision of the biased forecast. So if analysts are overconfident they will attach greater weight to the private signal than would be justified by the empirical precision.

If on the other hand analysts recognize that the forecasts of others are biased, they will be able to make appropriate correction for the bias. Then one can show that forecasts take the form:

$$
F_{t, t-1}^{B, i}-\hat{A}_{t, t-1}=\left(1-w_{i}^{B}\right)\left(F_{t, t-1}^{i-1}-\hat{A}_{t, t-1}\right)+w_{i}^{B} S_{t, t-1}^{i}
$$

where

$$
w_{i}^{B}=\frac{\left(1+a_{i}\right) \pi_{\eta}^{i}}{\pi_{\varepsilon}+\sum_{j=1}^{i-1} \pi_{\eta}^{j}+\left(1+a_{i}\right) \pi_{\eta}^{i}}
$$

(see Appendix A.2) This has a natural interpretation. If analysts recognize that the forecasts of others are biased, then simply by observing past data on actual earnings changes and forecasts they can infer the magnitude of the bias. This allows them to correct for the presence of the bias and to infer what the unbiased forecast, $F_{t, t-1}^{i-1}$, would be. We also show in the Appendix that the efficient forecasts depend on the biased forecasts in the following way:

$$
F_{t, t-1}^{i-1}=\frac{w_{i-1}}{w_{i-1}^{B}}\left(F_{t, t-1}^{B, i-1}\right)+\left(1-\frac{w_{i-1}}{w_{i-1}^{B}}\right)\left(F_{t, t-1}^{i-2}\right)
$$


By recursively substituting (12) into (11) one obtains an expression for the $\mathrm{i}^{\text {th }}$ observed forecast that depends upon all previously observed forecasts. The weights on past forecasts decline in an approximately geometric fashion. For example, if $\pi_{\varepsilon}=1, \pi_{\eta}^{i}=0.1$ and $a_{i}=1$ for all $i$, we find that the pattern of weights on past forecasts is as shown in Figure 3.

This gives us a simple way to distinguish between the two hypotheses. We regress the $\mathrm{i}^{\text {th }}$ forecast earnings change on all previous forecast changes and the actual earnings change. If analysts view the forecasts of others as unbiased then only the immediately preceding forecast and the actual earnings change should have non-zero coefficients. On the other hand, if analysts recognize and compensate for the bias in preceding forecasts, we will find non-zero coefficients on earlier forecasts. We report in Section V the results of such a test showing clearly that prior forecasts are not treated as if they were unbiased. That is, analysts recognize the existence of bias in others, but not in themselves.

\section{B. Biases of Self-deception: Cognitive Dissonance}

Cognitive dissonance describes the psychological discomfort that accompanies evidence that contradicts one's prior beliefs or world-view. To avoid this psychological discomfort, people tend to ignore, reject or reinterpret any information that conflicts with their prior beliefs. There are many studies that document this effect. For example, a study of the banking industry found that bank executive turnover predicted both provision for loan loss and the write-off of bad loans (Staw, Barsade and Koput, 1997). Higher turnover was associated with higher loan loss provision and more write-offs. The authors interpret this as evidence that the individuals responsible for making the original loan decisions exhibited systematic bias in their interpretation of information about the status of the loans. Scherbina and Jin (2005) describe a similar effect among mutual fund managers. New fund managers are more likely to sell momentum losers that they have inherited from their predecessors since they are not as committed to the investment decisions that led to those holdings. We hypothesize that earnings forecasts will be subject to a similar bias. If an analyst forms a favorable opinion of a company and issues an optimistic forecast, subsequent information will tend to be interpreted in a positive light, and conversely.

To incorporate cognitive dissonance, we introduce a distinction between the true or objective signal and the perceived signal. The perceived signal is influenced by whether the 
analyst has observed particularly favorable or unfavorable signals in the past. We model this effect by assuming that the perceived private signal $S_{t, t-1}^{B, i}$ differs from the objective signal by a mean shift that is a linear function of the forecast error in the previous period.

$$
S_{t, t-1}^{B, i}=S_{t, t-1}^{i}+k\left(F_{t-1, t-2}^{i}-A_{t-1}\right)=A_{t}-\hat{A}_{t, t-1}+\eta_{t-1}^{i}+k\left(F_{t-1, t-2}^{i}-A_{t-1}\right)
$$

Thus a positive forecast error generated by an unduly optimistic forecast causes the analyst to interpret her private signal next period too favorably. The size of the bias is measured by the coefficient $k$. The theory of cognitive dissonance predicts that $k$ will be positive.

With biases of overconfidence and cognitive dissonance the first analyst's one-periodahead forecast is

$$
\begin{aligned}
& F_{t, t-1}^{B, 1}-\hat{A}_{t, t-1}=w_{1}^{B} S_{t, t-1}^{B, 1} \\
& =w_{1}^{B}\left(A_{t}-\hat{A}_{t, t-1}+\eta_{t-1}^{1}+k\left(F_{t-1, t-2}^{B, 1}-A_{t-1}\right)\right)
\end{aligned}
$$

where $w_{1}^{B}$ is defined as before. ${ }^{11}$

Then the first efficient forecast is:

$$
F_{t, t-1}^{1}-\hat{A}_{t, t-1}=\frac{w_{1}}{w_{1}^{B}}\left(F_{t, t-1}^{B, 1}-\hat{A}_{t, t-1}-w_{1}^{B} k\left(F_{t-1, t-2}^{B, 1}-A_{t-1}\right)\right)
$$

If the second analyst recognizes the presence of both biases in the previous forecast, her forecast will be

$$
\begin{aligned}
& F_{t, t-1}^{B, 2}-\hat{A}_{t, t-1}=\left(1-w_{2}^{B}\right)\left(\frac{w_{1}}{w_{1}^{B}}\left(F_{t, t-1}^{B, 1}-\hat{A}_{t, t-1}-w_{1}^{B} k\left(F_{t-1, t-2}^{B, 1}-A_{t-1}\right)\right)\right) \\
& +w_{2}^{B}\left(A_{t}-\hat{A}_{t, t-1}+k\left(F_{t-1, t-2}^{B, 2}-A_{t-1}\right)+\eta_{t-1}^{2}\right)
\end{aligned}
$$

In general then the forecast of analyst $i$ will depend on all prior forecasts for the current period and on the corresponding lagged forecasts.

\section{Estimation of the Rational Model}

\section{A. Data}

Our data set consists of all quarterly earnings forecasts from the I/B/E/S Detail History database from 1993-1999. Actual earnings are obtained from the I/B/E/S Actuals File. To ensure a minimum level of accuracy in our parameter estimates, firms must have at least twelve quarters of seasonally differenced earnings data to be included in our study. To eliminate potential outliers, we follow the literature and apply several cumulative data filters. Because the forecast 
properties of "penny-stocks" may differ from the general sample, we remove observations when the stock price is below \$5 (Filter A). To ensure that the forecasts in our study come from analysts actively following the forecasted firms, we remove observations for analysts who issue fewer than 25 forecasts over the entire sample period. We also remove forecasts occurring on multiple-forecast days, which we use as a proxy for large new pieces of public information (Filter B). ${ }^{12}$ We restrict our sample to all quarterly earnings forecasts issued since the most recent quarterly earnings announcement (Filter C). Finally, to mitigate concerns about the influence of outliers ${ }^{13}$, we eliminate forecasts more than 6 standard deviations from actual (Filter D). Eliminating the inexperienced analysts and "penny” stocks has virtually no impact on our results. Including multiple forecast days or extreme observations (forecasts more than 6 standard deviations from actual) makes our estimates noisier, but does not affect the qualitative nature of our results.

\section{B. Pooling of Data}

Earnings vary considerably in both magnitude and volatility across firms. In addition, there exists significant cross-sectional variation in the firm-specific slope parameters in equation (11). It is common to adjust seasonally-differenced earnings by price (Rangan and Sloan 1998; Easterwood and Nutt 1999; Keane and Runkle 1998) or by a rolling 8-period estimate of standard deviation (Bernard and Thomas 1990; Chan, Jegadeesh and Lakonishok 1996). However, Friesen (2005) shows that cross-sectional variation in both the regression parameters and the scale of the underlying regression variables can lead to biased regression parameters. Friesen demonstrates that in many instances, normalizing by price fails to remove this variability, and as a result regression parameters estimated with price-normalized data may be biased. Therefore, we normalize the data using a more stable firm-specific volatility measure as follows: For each firm, we fit an AR(2) model to seasonally differenced earnings. ${ }^{14}$ In particular, for each firm $j$, we estimate parameters for the model:

$$
A_{j, t}=\mu_{j}+A_{j, t-4}+\rho_{j, 1}\left(A_{j, t-1}-A_{j, t-5}-\mu_{j}\right)+\rho_{j, 2}\left(A_{j, t-2}-A_{j, t-6}-\mu_{j}\right)+\varepsilon_{j, t}
$$

where $\varepsilon_{j, t} \sim N\left(o, \sigma_{j, \varepsilon}^{2}\right)$. Following Bernard and Thomas (1990), we use the entire sample period to estimate the parameters. The estimated standard deviation, $\sigma_{j, \varepsilon}$, is then used to normalize the firm’s earnings. We refer to data normalized in this way as sigma-normalized data. 
A possible objection to this method is that the normalizing factor is estimated using data not available at the time the forecast is made, possibly introducing a look-ahead bias. If we were using the estimated normalizing factor to help forecast future realizations of a variable, this might indeed induce a look-ahead bias. However, our regressions simply decompose the $i^{\text {th }}$ observed forecast into a weighted average of lagged forecasts and actual earnings. A second criticism is that our normalizing factor might be biasing the parameter estimates themselves. The key issue here is whether the normalizing factor, $\sigma_{j, \varepsilon}$, is correlated with the regression parameter, $\beta_{j}$. We have checked this and found that the factor is uncorrelated with model parameters.

Because our model predicts a specific relationship between forecast error variance and regression error variance, pooled parameter estimates must be based upon appropriately normalized data. Both price-normalized and actual data have cross-sectional heteroskedasticity approximately four to seven times as severe as that of sigma normalized data. In light of this statistic and the results of Friesen (2005), we feel that our methodology is the most sensible way to achieve stability in the scale of variables across firms, while maintaining the relative dispersions required for calculating valid measures of within-firm variance.

Table I provides some basic sample statistics for our data. Panel A uses actual data, and panel B gives identical statistics for sigma-normalized data. Of particular interest is that moving from Filter $\mathrm{C}$ to Filter D has minimal impact on the mean, median and standard deviation of most variables, but the minimum and maximum values of analyst forecast and forecast error are significantly affected. Note the minimal impact on extreme values of actual earnings. Keane and Runkle (1998) eliminate outliers by removing actual earnings observations greater than 4 standard deviations from the mean. By contrast, we eliminate all observations associated with forecast errors greater than 6 standard deviations from the mean. ${ }^{15}$ The most extreme values of actual earnings are unaffected, suggesting that analysts were able to forecast those extreme values no less accurately. Eliminating outliers based on extreme forecast errors removes the biggest true surprises.

\section{A Comparison of the Rational and Cognitive Bias Models}

We are interested in distinguishing between three separate hypotheses: (i) forecasts are rational (ii) forecasts are biased and individuals do not recognize the bias in others (iii) forecasts 
are biased but individuals do recognize the bias in others. Previous work has not explicitly attempted to discriminate between (ii) and (iii). However, our analysis in the previous section has shown that it is important to do this if we are to have a properly specified model.

We first run the regressions described at the end of Section IV.A. We regress the $\mathrm{iP}^{\text {th }}$ forecast earnings change on all previous forecast changes and the actual earnings change. As we argued above, if analysts view the forecasts of others as rational then only the immediately preceding forecast and the actual earnings change should have non-zero coefficients. The results presented in Table II show that this is clearly not the case. The weights on past forecasts decline in a way that is qualitatively similar to those illustrated in Figure 3, which were derived from a numerical example. This is evidence against both hypothesis (i) and hypothesis (ii). It also allows us to conduct a formal test to discriminate between (i) and (iii) using the generalized method of moments (GMM). Since the rational and non-rational models are nested we can use the NeweyWest (1987) D-test to discriminate between them. The difference between the models is that in the rational model, the overconfidence and cognitive dissonance variables ( $a$ and $k$ ) are constrained to equal zero. Technical details on the estimation procedure, including moment conditions and the specification of the D-test are contained in Appendix B.

Estimating the models requires us to make several assumptions. First, we assume that cognitive bias parameters are constant across analysts and through time. As such, our estimates can be interpreted as measures of the average level of cognitive bias among analysts. Second, private signal precision is aggregated across analysts, again yielding an estimate of the average signal precision for each ordered forecast. Third, we ignore the effect of dissonance bias other than for the issuer of the current forecast. That is, analyst $i$ exhibits overconfidence and cognitive dissonance, and also recognizes and adjusts for overconfidence in previous forecasts. Analyst $i$ does not adjust for the cognitive dissonance bias in other analyst forecasts. ${ }^{16}$ Fourth, in the biased model, the efficient consensus is calculated endogenously as a weighted average of all previously issued forecasts, where the weights are functions of the estimated cognitive bias parameters, as well as the estimated weights each past analyst placed on her private information.

The results from estimating the rational model and the model with cognitive biases are presented in Table III. ${ }^{17}$ The equations of the model are estimated with a constant to allow us to identify optimism bias. We find clear evidence of such a bias, although it declines steadily over the quarter and has disappeared by the eighth forecast and is replaced by a pessimism bias. Its 
magnitude is very similar in both models. The most striking difference between the parameter estimates generated by the two models occurs for private signal precision. Figures for the rational model are consistently much larger than those for the model with bias. To understand this result, it is helpful to think intuitively about the source of the parameter estimates. In both models, the current $\left(i^{\text {th }}\right)$ forecast is generated by a weight on the efficient consensus and a weight on the private signal. The weight on the private signal, along with the estimated regression error variance, yields an unbiased estimate of the precision of the $i^{\text {th }}$ signal. The rational model imposes the additional restriction that private signal precision be internally consistent with the actual weight attached to the private signal. If the actual weight is set too high then this will introduce an upward bias in the estimate of private signal precision.

The values of the cognitive bias parameters $a$ and $k$ are both positive and highly significant. The Newey-West D-test resoundingly rejects the rational model (p-value $<10^{-20}$ ). The parameter $a$ has a value of 0.937 and a standard error of 0.027 . This means that analysts attach roughly double the rational weight to their private information. The parameter $k$ has a value of 0.079 and a standard error of 0.007 . Thus an analyst's past forecast error has an effect on her current forecast in the direction predicted by the theory of cognitive dissonance. If the previous forecast error was positive, indicating that the analyst's private information was relatively favorable, the beliefs formed on the basis of this information induce a positive bias in the perception of the current private signal.

However, the economic significance of the two variables differs. We can illustrate this by calculating the impact of overconfidence alone on forecast accuracy. We compare the precision of the $\mathrm{i}^{\text {th }}$ ordered forecast with the precision of the $\mathrm{i}^{\text {th }}$ efficient consensus forecast. The $\left(\mathrm{i}^{\text {th }}\right)$ efficient forecast is a weighted average of the current $\left(\mathrm{i}^{\text {th }}\right)$ and past forecasts, with weights calculated according to equation (11). The difference between the efficient forecast precision and the actual forecast precision represents the efficiency loss due to overweighting private information and cognitive dissonance biases. Figure 4 expresses this efficiency loss as a percentage of the actual forecast precision. The effect of analyst bias is dramatic, reducing forecast precision by $5 \%$ to $30 \%$ depending on forecast order. In contrast, the isolated effect of the dissonance parameter $k$ is limited. If we look at the distribution of (non-normalized) forecast errors in our sample, we find that three quarters of all forecasts have an absolute error of 7 cents or less per share. For these forecasts a value of $k=0.1$ produces a bias of less than one penny per 
share. Five per cent of all forecasts have absolute errors of more than 28 cents. For these forecasts the bias is two cents per share or more.

An interesting feature of our results is that analysts do not view the forecasts of others as fully rational, but do not extend this perception to correct the bias in their own forecasts. This is consistent with psychological theories that emphasize self-serving bias in causal attribution (Miller and Ross, 1975). This bias involves individuals attributing their own successes to skill and their failures to chance. The reason for the existence of such a bias may be that it enhances self-esteem and protects from the negative impact of a sense of failure. Additionally, it has been argued that there may be an effect working through expectations. If outcomes are as expected they are attributed to ability, and if they are not they are attributed to chance. Miller and Ross argue that people are more likely to expect to succeed rather than to fail in task-oriented situations, hence the tendency to believe that success is due to ability. The presence of such a bias provides an explanation for the fact that individuals find it much more difficult to learn about biases in their own behavior than about those in others.

\section{Testing Predictions of the Cognitive Bias Model}

\section{A. Theoretical Predictions of Incentive-Based and Psychological Models}

Our analysis of forecasting behavior assumes that analysts issue forecasts that correspond to their true expectations. However, several authors have argued that there may be various incentives which lead analysts to issue forecasts that deviate systematically from their true expectations. This question is typically examined in an environment in which analysts differ in ability. Those with low skill want to appear like those with high skill, but the latter want to differentiate themselves from the low skill group. Trueman (1994) constructs a model in which such incentives induce analysts to underweight their own private information and to display a propensity to "follow the herd". If analysts are indeed subject to this pressure, then our measure of overconfidence is biased downwards, since our results demonstrate that the net effect of rational incentives and overconfidence leads to overweighting. There are a number of other papers not focused explicitly on analysts' forecasts that also conclude that there are pressures to engage in herding behavior when actions such as investment decisions reveal information about ability (Scharfstein and Stein 1990, Prendergast and Stole 1996). 
Ehrbeck and Waldmann (1996) show that under different assumptions it is possible for a rational incentive for overweighting private information to emerge. However, in their model analysts make forecasts only over one or two periods. In such a situation using forecast accuracy as a measure of ability is relatively uninformative, since there is a large amount of sampling error and there is scope for the deviation of a forecast from the consensus to transmit significant additional information about private signal precision. So there is a tradeoff between the incentive to forecast accurately and the incentive to overweight one's private information to signal that the information is more precise than it really is. However one would expect such an incentive to decline rapidly in significance the more forecasts an analyst makes. ${ }^{18}$ We include analysts in our sample only if they have made at least 25 forecasts. Many have made several hundred. For example, of the 3,594 analysts in our sample, the mean analyst issues 85 forecasts. Twenty-five percent of our sample, or about 900 analysts, have issued at least 111 forecasts, while ten percent of our sample, or 359 analysts, have issued at least 213 forecasts. In these circumstances it is not obvious why any significant incentive to exaggerate should persist. We have shown above in Figures 4 and 5 that the effect of overconfidence on forecast accuracy is large. Given analysts' clear incentive to issue accurate forecasts (Mikhail, Walther and Willis (1999) find that lower relative forecast accuracy increases an analyst's chances of being fired), it would be implausible to attribute the observed behavior solely to signaling of ability.

We turn to considering additional implications of the cognitive bias model. The psychology literature consistently demonstrates that overconfidence tends to be most pronounced in situations where information is ambiguous and predictability is low (Griffin and Tversky 1992) and the task is of moderate to extreme difficulty (Fischoff, Slovic and Lichtenstein, 1982). Similarly, Clark's (1960) signal detection research suggests that individuals are most prone to overconfidence when the precision of a signal is low. If our empirical estimates represent overconfidence, then cross-sectional variation in the estimates should be consistent with these findings. Based on these studies, we hypothesize that overconfidence will be most pronounced for firms where information is ambiguous and the quality of information is low.

Daniel and Titman (1999) use this prediction to generate an indirect test of the asset pricing model of Daniel, Hirshleifer and Subrahmanyam (1998) based on overconfidence. They argue that since valuation of low book-to-market (B-M) firms involves a greater degree of uncertainty and ambiguity, the findings from the psychology literature cited above imply that 
overconfidence should be greater for this group of firms. The model predicts that momentum effects should be higher the higher the level of overconfidence, leading to the hypothesis that such effects should be higher for low B-M firms than for high B-M firms. They find strong evidence that this is the case. If their argument is correct we should find that our measure of overconfidence is higher among low B-M firms than high B-M firms.

To examine this issue, we obtain B-M data from the Compustat Industrials file, and define the B-M ratio as the book value of equity (item 60) divided by the market value of equity (item 24 times item 25). Forecasts are divided into high, low, and medium B-M quartiles based

on the cross-sectional distribution of B-M ratios as of the previous fiscal year end. ${ }^{19}$ Following Fama and French (1992), we include a six-month lag between the previous fiscal year-end and our forecasts. Thus, for a firm with a December fiscal year-end, the firm's forecasts issued between July 1 of year $t$ and June 30 of year $t+1$ are sorted based on the firm's B-M ratio as of the previous fiscal year-end $(t-1)$.

Table IV contains parameter estimates, and reveals a significant association between overconfidence and B-M ratios. The value of $a$ for low B-M firms is 1.04 with a standard error of 0.046, while for high B-M firms it is 0.75 with a standard error of 0.050 . Likewise, the cognitive dissonance bias is nearly twice as strong amongst low B-M firms. The value of $k$ for low B-M firms is 0.103 with a standard error of 0.014 versus a value for high B-M firms of 0.028 with a standard error of 0.015. Thus, the subset of firms for which Daniel and Titman (1999) find the strongest momentum effect also have the strongest cognitive biases.

\section{B. Asymmetric Cognitive Dissonance Bias}

As with overconfidence, some studies have suggested that the correlation between current and lagged forecast errors, which we attribute to cognitive dissonance, may be due to incentives. For instance, Chan, Jegadeesh and Lakonishok (1996, p.1710) suggest that “analysts are especially slow in revising their estimates in the case of companies with the worst performance. This may possibly be due to their reluctance to alienate management.” This leads one to predict that analysts will update their beliefs too slowly when their past forecasts have been too high, but will rationally update their beliefs when their forecasts have been too low. In contrast, cognitive dissonance theory suggests that analysts will be slow to update their beliefs regardless of the sign of past forecast error. Easterwood and Nutt (1999) and Kasznick and McNichols (2002) find 
evidence consistent with the incentive argument: when analyst forecasts are too high, subsequent forecasts tend to stay too high; but when analyst forecasts are too low, subsequent forecasts are either unbiased (Kasznick and McNichols 2002), or become too high (Easterwood and Nutt 1999).

Following the methodology in Easterwood and Nutt (1999), we divide our sample into quartiles based on the sign and magnitude of lagged forecast errors. We define lagged forecast error as lagged forecast minus lagged actual earnings. We label the top quartile of observations "High Positive Lagged Error", the bottom quartile "High Negative Lagged Error" and the middle two quartiles "Low Lagged Error". We estimate the model separately for each sub-sample, and present the results in Table V. Overconfidence levels are highest among the high positive and high negative quartiles of lagged error, and there is no significant difference between the two groups. Thus we see no evidence that overreaction to new information, which is the defining characteristic of overconfidence, is influenced in the way that an incentive-based argument would suggest. What we do observe is that the level of overconfidence is significantly lower in the Low Lagged Error subsample and that the quality of private information as measured by private signal precision is higher. This is consistent with the experimental findings cited above in which individuals are found to be more overconfident in situations where information is of lower quality.

Cognitive dissonance is most evident among the low lagged forecast errors (i.e. when lagged absolute forecast errors are relatively small). The dissonance bias is also significant among high negative lagged error forecasts (i.e. when the lagged analyst forecast was "too pessimistic"). The dissonance bias is insignificant among high positive lagged error forecasts (i.e. when the lagged analyst forecast was "too optimistic"). These findings run counter to the incentive-based predictions of Chan, Jegadeesh and Lakonishok (1996) but the cause of the observed asymmetry remains obscure.

\section{International Evidence \\ Experimental studies have revealed systematic cross-cultural variations in} overconfidence. Asian subjects regularly display higher levels of overconfidence than their Western counterparts (Wright et al. 1978, Lee et al. 1995). Among Asian subjects the Japanese display lower levels of overconfidence (Yates et al. 1989, 1990). In a detailed survey on cultural 
perceptions of overconfidence, Yates et al. (1996) find that most Americans express surprise, and sometimes skepticism, when told that Asians are more overconfident than Americans. Moreover, while many studies measure overconfidence using general knowledge questions, Yates et al. (1998) demonstrate that the same cross-cultural variations exist in practical decisionmaking contexts. If the analyst behavior documented in section IV is indeed due to overconfidence, then we should expect our estimates of overconfidence to vary across countries in a manner consistent with the psychological evidence.

\section{C.1. International Data Sources}

Our data set consists of all annual earnings forecasts from the I/B/E/S International Detail History database and I/B/E/S Domestic Detail History database from 1993-1999. Whereas analysts in the United States tend to issue both quarterly and annual earnings forecasts for firms, most international forecasts are issued only for annual earnings. Thus, while previous sections of the paper used quarterly US earnings forecasts to estimate the model, this section utilizes annual US forecasts to provide a consistent basis for comparison with other countries.

To ensure a minimum level of accuracy in our parameter estimates, firms must have at least four years of annually-differenced earnings data to be included in our study. To eliminate potential outliers, we apply the same data filters as for quarterly data. Filter $\mathrm{C}$ is appropriately modified to apply to annual earnings forecasts so that our sample is restricted to all annual forecasts issued since the most recent annual earnings announcement.

We normalize the data using a firm-specific volatility measure as follows: for each firm $j$,

we calculate the variance of annually-differenced earnings $\sigma_{\varepsilon, j}^{2}=\operatorname{Var}\left(A_{j, t}-A_{j, t-1}\right)$. As before, we use the entire sample period to estimate the parameters. The estimated standard deviation, $\sigma_{\varepsilon, j}$, is then used to normalize the firm's earnings. We refer to data normalized in this way as sigma-normalized data.

\section{C.2. Estimation Results for Annual US Forecasts}

Table VI contains parameter estimates for annual US earnings forecasts. Comparing the results of Table VI to those of Table II (quarterly US earnings forecasts) reveals that the properties of quarterly and annual US forecasts are similar. As with quarterly forecasts, the unconditional annual consensus forecast precision increases sequentially with forecast order (in 
both data sets, the forecast precision of the $15^{\text {th }}$ ordered forecasts is about double the forecast precision of the second forecast). ${ }^{20}$

Overconfidence parameter estimates are higher with annual data $(a=1.141)$ than with quarterly data $(a=0.937)$. Given the increase in uncertainty associated with annual forecasts this finding is consistent with the experimental evidence cited above. In the next section, we compare the properties of annual US earnings forecasts to those of international earnings forecasts.

\section{C.3. Cross-Country Parameter Estimates}

Table VI presents parameter estimates from annual earnings forecasts for the US and Japan. The sequential increase in consensus forecast precision in Japan is similar to patterns in US data. This precision increases with each sequential forecast. Private signal precisions are in general substantially higher in the US than in Japan, suggesting that Japanese analysts have relatively less private information than US analysts.

Analysts in Japan exhibit higher levels of overconfidence than their American counterparts. The overconfidence parameter in Japan is 1.575 with a standard error of 0.147. We also find that the level of private signal precision is overall substantially lower in Japan. This means that there are potentially confounding effects on the measured level of overconfidence. On the one hand, poorer quality of information will tend to increase overconfidence, whereas the international experimental evidence cited above (Yates et al. 1989, 1990) would lead one to expect lower levels of overconfidence in Japan than in the US.

We also look at cognitive bias parameter estimates for other East Asian nations and for Western Europe. We calculate estimates from a pooled sample of annual earnings forecasts from China, Hong Kong, India, Indonesia, Malaysia, the Philippines, Singapore, Taiwan, South Korea and Thailand. Overconfidence among these countries is somewhat higher than in the US ( $a=$ 1.382 with a standard error of 0.107) although the difference is not significant. Given that levels of private signal precision are broadly comparable with those in the US (details omitted), this finding is (weakly) consistent with the experimental evidence.

In the case of Western Europe, the results from estimating the model on aggregate data give an estimate of 1.006 for the overconfidence parameter with a GMM standard error of 0.062. Thus we find that the results from our analysis of international data confirm the general finding 
for the US, that analysts display overconfidence and that this has a substantial impact on earnings forecasts.

\section{Conclusion}

We have presented a model of sequential earnings forecasts that enables us to use information on the second moment of forecast errors to test whether the forecasts are unbiased. We find strong evidence to suggest that analysts place too much weight on their private information, consistent with the model of investor overconfidence in Daniel, Hirshleifer and Subrahmanyam (1998). We also show that past forecast errors influence current forecasts in a manner predicted by the theory of cognitive dissonance. We argue that these results are unlikely to have arisen solely as a result of a rational response to incentives, and present evidence to support the view that the misweighting stems from cognitive biases. Our results are consistent with findings in other fields. As Hirshleifer (2001) points out in his review of investor psychology, experts in many fields systematically suffer from these biases. We show also that the bias generated by overconfidence is sufficiently large to be of economic significance. Analysts place twice as much weight on their private information as is justified by rational Bayesian updating.

In our framework in which analysts issue forecasts sequentially it becomes important to address the issue of how analysts interpret the forecasts of others. Our model delivers a simple test to determine whether analysts view other forecasts as unbiased or not. The test indicates that analysts make corrections for bias in the forecasts of others even though their own forecasts are subject to the same biases.

We examine the way in which information quality proxied by the book-to-market ratio influences our measures of overconfidence and cognitive dissonance, and find strong effects consistent with experimental findings in the psychology literature. We show that the level of overconfidence varies with the firm's book-to-market ratio in a manner consistent with the model of Daniel, Hirshleifer and Subrahmanyam (1998) and the empirical findings of Daniel and Titman (1999). We also look at international data on the level of overconfidence and find some weak evidence that our measure varies as predicted by psychological experiments.

Our model enables us to quantify cognitive biases across a large cross-section of stocks. This, in turn, will allow us to address a further series of questions relevant for assessing asset 
pricing models based on investor overconfidence. Are the biases we measure associated with the presence of price momentum? Does the magnitude of average cognitive bias vary with pricedividend or price-earnings ratios through time? These questions are ones we intend to pursue in future research. 


\section{References}

Abarbanell, J.S., 1991, Do analysts' forecasts incorporate information in prior stock price changes? Journal of Accounting and Economics, 14, 147-165.

Abarbanell, J.S.and Victor Bernard, 1992, Tests of analysts' overreaction/underreaction to earnings information as an explanation for anomalous stock price behavior, Journal of Finance, 47, 1181-1208.

Abarbanell, J. and R. Lehavy, 2000, Differences in commercial database reported earnings: Implications for inferences concerning analyst forecast rationality, the association between prices and earnings, and firm reporting discretion, Working Paper, University of North Carolina.

Akerlof, G. A. and W. T. Dickens, 1982, The economic consequences of cognitive dissonance, The American Economic Review, 72, 307-319.

Barberis, Nicholas, Andrei Shleifer and Robert Vishny, 1998, A model of investor sentiment, Journal of Financial Economics, 49, 308-343.

Berg, E., May 15, 1990, Risks for analysts who dare say sell, New York Times, pp. C1,C6.

Bernard, Victor, and Jacob Thomas, 1990, Evidence that stock prices do not fully reflect the implications of current earnings for future earnings, Journal of Accounting and Economics, 13, 305-341.

Brown, L, and M. Rozeff, 1978, The superiority of analyst forecasts as measures of expectations: evidence from earnings, Journal of Finance, 33, 1-16.

Brown, L., L. Hagerman, P. Griffin, and M. Zmijewski, 1987, Security analyst superiority relative to univariate time-series models in forecasting quarterly earnings. Journal of Accounting and Economics, 9, 61-87.

Brown, L, 1997, Analyst forecasting errors: additional evidence, Financial Analysts Journal, 53, 81-89.

Chan, L., Jegadeesh, N., Lakonishok, J., 1996, Momentum strategies. Journal of Finance 51, 1681-1713.

Chen, Qi, and Wei Jiang, 2005, Analysts’ Weighting of private and public information, Review of Financial Studies, forthcoming.

Clark, F. R., 1960, Confidence ratings, second-choice responses and confusion matrices in intelligibility tests, Journal of the Acoustical Society of America, 32, 35-46. 
Cochrane, John, 2001, Asset Pricing, Princeton University Press: Princeton, NJ.

Cooper, Rick A., Theodore E. Day and Craig M. Lewis, 2001, Following the Leader: A Study of Individual Analysts' Earnings Forecasts, Journal of Financial Economics. Volume 61(3), 383-416.

Daniel, Kent D., David Hirshleifer and Avanidhar Subrahmanyam, 1998, Investor psychology and security market under- and overreactions, Journal of Finance, 53, 1839-1885.

Daniel, Kent D., David Hirshleifer, and Avanidhar Subrahmanyam, “Overconfidence, Arbitrage and Equilibrium Asset Pricing,” Journal of Finance, 56, 2001, 921-965.

Daniel, Kent D. and Sheridan Titman, 1999, Market Efficiency in an Irrational World, Financial Analysts' Journal 55, 28-40.

DeBondt, W.F.M., Thaler, R.H., 1990. Do security analysts overreact? American Economic Review, 80, 52-57.

Easterwood, J., and S. Nutt, 1999, Inefficiency in analysts' earnings forecasts: systematic misreaction or systematic optimism?, Journal of Finance, 54, 1777-1797.

Ehrbeck, T., and R. Waldmann, 1996, Why are professional forecasters biased? Agency versus behavioral explanations, Quarterly Journal of Economics, 111, 21-40.

Fama, Eugene F., 1998, Market efficiency, long-term returns, and behavioral finance, Journal of Financial Economics 49, 283-306.

Fama, Eugene F., and Kenneth French, 1992, The cross-section of expected stock returns, Journal of Finance, 47, 427-465.

Festinger, L., 1957, A theory of cognitive dissonance. Evanston, IL: Row, Peterson.

Fischoff, B., P. Slovic and S. Lichtenstein, 1982, Calibration of probabilities: The state of the art to 1980, in Daniel Kahneman, Paul Slovic and Amos Tversky, ed.: Judgement under Uncertainty: Heuristics and Biases (Cambridge University Press, Cambridge).

Fried, D., and D. Givoly, 1982, Financial Analysts' forecasts of earnings: A better surrogate for market expectations, Journal of Accounting and Economics, 4, 85-107.

Friesen, G., 2005, A note on the dangers of analyzing price-normalized earnings forecasts, Working Paper, University Of Nebraska-Lincoln

Givoly, D., Lakonishok, J., 1984. The quality of analysts' forecasts of earnings, Financial Analysts Journal, 40, 40-47. 
Gleason, C. and C. Lee, 2002, Characteristics of price informative analyst forecasts, working paper, University of Arizona.

Goetzmann, W. and N. Peles, 1997, Cognitive dissonance and mutual fund investors, Journal of Financial Research, 20, 145-158.

Graham, J.R., 1999, Herding among investment newsletters: Theory and evidence, Journal of Finance, 54, 237-268.

Greene, W.H., 1997, Econometric Analysis, Prentice Hall: Upper Saddle River, NJ.

Griffin, D., Tversky, A., 1992. The weighing of evidence and the determinants of confidence, Cognitive Psychology, 24, 411-435.

Hansen, L. P., 1982, Large sample properties of generalized method of moments estimators, Econometrica, 50, 1029-1054.

Hirshleifer, David, 2001, Investor psychology and asset pricing, Journal of Finance, 56, 15331597.

Hong, Harrison, Jeffery Kubik and Amit Solomon, 2000, Security analysts' career concerns and herding of earnings forecasts, RAND Journal of Economics, 31, 121-144.

Jones, E. E. (1985). Major developments in social psychology during the past five decades. In G. Lindzey \& E. Aronson (Eds.), The handbook of social psychology (3rd ed., pp. 47-108). New York: Random House.

Kasznick, R. and M. McNichols, 2002, Does meeting expectations matter? Evidence from analyst forecast revisions and share prices, Journal of Accounting Research, 40, 727-759.

Keane, M., and D. Runkle, 1998, Are financial analysts' forecasts of corporate profits rational?, Journal of Political Economy, 106, 768-805.

Klein, A., 1990, A direct test of the cognitive bias theory of share price reversals, Journal of Accounting and Economics, 13, 155-166.

Lamont, O., 1995, Macroeconomic forecasters and microeconomic forecasts, NBER Working Paper \#5284.

LaPorta, R., 1996, Expectations and the cross-section of stock returns, Journal of Finance, 51, 1715-1742.

Lee, J., J. F. Yates, H. Shinotsuka, R. Singh, M. L. U. Onglatco, N. S. Yen, M. Gupta, D. Bhatnagar, 1995, Cross-national differences in overconfidence, Asian Journal of Psychology, 1, 63-69. 
Lim, T., 2001, Rationality and analysts' forecast bias, Journal of Finance, 56, 369-385.

Mendenhall, R., 1991, Evidence on the possible underweighting of earnings-related information, Journal of Accounting Research, 29, 170-179.

McNichols, M. and P. O'Brien, and J. Francis, 1997, Self-selection and analyst coverage, Journal of Accounting Research, 35, 167-208.

Michaely and Womack, 1999, Conflict of interest and credibility of underwriter analyst recommendations, Review of Financial Studies, 12, 653-686.

Mikhail, M., B. Walther and R. Willis, 1999, Does forecast accuracy matter to security analysts?, The Accounting Review, 74, 185-200.

Miller, D.T. and M. Ross, 1975, Self-serving biases in the attribution of causality: fact or fiction? Psychological Bulletin 82, 213 -25.

Newey, Whitney, and Kenneth West, 1987, Hypothesis testing with efficient method of moments, International Economic Review, 28, 777-787.

Odean, Terrance, 1998, Volume, volatility, price and profit when all traders are above average, Journal of Finance, 53, 1887-1934.

Ottaviani, M., and P. N. Sorensen, 2001, The strategy of professional forecasting, Working Paper, University College London.

Prendergast, Canice and Lars Stole, 1996, Impetuous youngsters and jaded old-timers: Acquiring a reputation for learning, Journal of Political Economy, 104, 1105-1131.

Rangan, S., and R. Sloan. "Implications of the Integral Approach to Quarterly Reporting for the Post-Earnings-Announcement Drift." The Accounting Review (July 1998): 353-371.

Richardson, S., S. Teoh and P. Wysocki, 1999, Tracking analysts' forecasts over the annual earnings horizon: Are analysts' forecasts optimistic or pessimistic? working paper, University of Michigan.

Scharfstein, D. and J. Stein, 1990, Herd behavior and investment, The American Economic Review, 80, 465-479.

Scherbina, Anna and Jin, Li, 2005, "Change is Good or the Disposition Effect Among Mutual Fund Managers," EFA 2005 Moscow Meetings Paper.

Schultz, E., April 23, 1990, Analysts who write lukewarm sometimes get burned, The Wall Street Journal. 
Shane, Philip and Peter Brous, 2001, Investor and (value line) analyst underreaction to information about future earnings: The corrective role of non-earnings-surprise information, Journal of Accounting Research, 39, 387-404.

Siconolfi, M. 1995. Many companies press analysts to steer clear of negative ratings. Wall Street Journal (July 25, 1995): A1, C6.

Staw, Barry M., Sigal G. Barsade and Kenneth W. Koput, (1997) "Escalation at the Credit Window: A Longitudinal Study of Bank Executives' Recognition and Write-Off of Problem Loans,” Journal of Applied Psychology 82, 130-142.

Stickel, Scott, 1990, Predicting individual analyst earnings forecasts, Journal of Accounting Research, 28, 409-417.

Trueman, B., 1994, Analysts forecasts and herding behavior, Review of Financial Studies, 7, 97124.

Wright, G. N., L. D. Phillips, P. C. Whalley, G. T. Choo, K. O. Ng, I. Tan and A. Wisudha, 1978, Cultural differences in probabilistic thinking, Journal of Cross-Cultural Psychology, $15,239-257$.

Yates, J. F., Y. Zhu, D. L. Ronis, D. F. Wang, H. Shinotsuka and M. Toda, 1989, Probability judgment accuracy: China, Japan and the United States, Organizational Behavior and Human Decision Processes, 43, 145-171.

Yates, J. F., J.-W. Lee, K. R. Levi and S. P. Curley, 1990, Measuring and analyzing probability judgement accuracy in medicine, Philippine Journal of Internal Medicine, 28 (Suppl. 1), 2132.

Yates, J. F., J.-W. Lee and H. Sinotsuka, 1996, Beliefs about overconfidence, including its crossnational variation, 1996, Organizational Behavior and Human Decision Processes, 65, 138147.

Yates, J. F., J.-W. Lee, H. Sinotsuka, A. L. Ptalano and W. R. Sieck, 1998, Cross-cultural variations in probability judgement accuracy: Beyond general knowledge overconfidence? Organizational Behavior and Human Decision Processes, 74, 89-117.

Zitzewitz, E., 2001a, Measuring herding and exaggeration by equity analysts, Working Paper, MIT mimeo.

Zitzewitz, E., 2001b, Opinion-producing agents: career concerns and exaggeration, MIT mimeo. 


\section{Appendix A.1}

We derive the results contained in (6). Since the first forecast during period $t-1$ is conditioned only on $I_{t-1}^{\text {public }}$ and the first private signal, it can be written

$$
F_{t, t-1}^{1}-\hat{A}_{t, t-1}=\frac{\pi_{\eta}^{1}}{\pi_{\varepsilon}+\pi_{\eta}^{1}} S_{t, t-1}^{1}=\frac{\pi_{\eta}^{1}}{\pi_{\varepsilon}+\pi_{\eta}^{1}}\left(\varepsilon_{t}+\eta_{t-1}^{1}\right)
$$

To show how the first forecast can be transformed into an unbiased signal about $\varepsilon_{t}$, we can write it as

$$
\frac{\pi_{\varepsilon}+\pi_{\eta}^{1}}{\pi_{\eta}^{1}}\left(F_{t, t-1}^{1}-\hat{A}_{t, t-1}\right)=\varepsilon_{t}+\eta_{t-1}^{1}
$$

The forecast of the second analyst will combine the second private signal with the forecast already issued. Using the rules for Bayesian updating, her expected earnings innovation is

$$
\begin{gathered}
E\left[\varepsilon_{t} \mid S_{t, t-1}^{2}, F_{t, t-1}^{1}\right]=\frac{\pi_{\eta}^{1}}{\pi_{\varepsilon}+\sum_{j=1}^{2} \pi_{\eta}^{j}}\left[\frac{\pi_{\varepsilon}+\pi_{\eta}^{1}}{\pi_{\eta}^{1}}\left(F_{t, t-1}^{1}-\hat{A}_{t, t-1}\right)\right]+\frac{\pi_{\eta}^{2}}{\pi_{\varepsilon}+\sum_{j=1}^{2} \pi_{\eta}^{j}} S_{t, t-1}^{2} \\
=\frac{\pi_{\varepsilon}+\pi_{\eta}^{1}}{\pi_{\varepsilon}+\sum_{j=1}^{2} \pi_{\eta}^{j}}\left(F_{t, t-1}^{1}-\hat{A}_{t, t-1}\right)+\frac{\pi_{\eta}^{2}}{\pi_{\varepsilon}+\sum_{j=1}^{2} \pi_{\eta}^{j}}\left(A_{t}-\hat{A}_{t, t-1}\right)+\frac{\pi_{\eta}^{2}}{\pi_{\varepsilon}+\sum_{j=1}^{2} \pi_{\eta}^{j}} \eta_{t-1}^{2}
\end{gathered}
$$

Remembering that

$$
w_{i}=\frac{\pi_{\eta}^{i}}{\pi_{\varepsilon}+\sum_{j=1}^{i} \pi_{\eta}^{j}}
$$

and noting that

$$
F_{t, t-1}^{2}=\hat{A}_{t, t-1}+E\left[\varepsilon_{t} \mid S_{t, t-1}^{2}, F_{t, t-1}^{1}\right]
$$

we find that

$$
F_{t, t-1}^{2}=\left(1-w_{2}\right) F_{t, t-1}^{1}+w_{2} A_{t}+w_{2} \eta_{t-1}^{2}
$$

and that in general

$$
F_{t, t-1}^{i}=\left(1-w_{i}\right) F_{t, t-1}^{i-1}+w_{i} A_{t}+w_{i} \eta_{t-1}^{i}
$$

which is the form of equation (6) in the text. 


\section{Appendix A.2}

We derive the results given in equations (11) and (12) of the text. The first analyst receives a private signal $S_{t, t-1}^{1}=\varepsilon_{t}+\eta_{t-1}^{1}$ with true precision $\pi_{\eta}^{1}$. Then the regression equation

$$
\varepsilon_{t}=b_{1} S_{t, t-1}^{1}+v_{t}^{1}
$$

has the property that $b_{1}=\frac{\operatorname{cov}\left(\varepsilon_{t}, S_{t, t-1}^{1}\right)}{\operatorname{var}\left(S_{t, t-1}^{1}\right)}=\frac{\pi_{\eta}^{1}}{\pi_{\varepsilon}+\pi_{\eta}^{1}} \equiv w_{1}$. The unbiased forecast conditional on $S_{t, t-1}^{1}$ is

$$
F_{t, t-1}^{1}=\hat{A}_{t, t-1}+w_{1} S_{t, t-1}^{1}
$$

and $v_{t}^{1}$ is the forecast error.

The first biased forecast is given by

$$
F_{t, t-1}^{B, 1}=\hat{A}_{t, t-1}+w_{1}^{B} S_{t, t-1}^{1}
$$

and it follows that

$$
A_{t}-\hat{A}_{t, t-1}=\varepsilon_{t}=w_{1} S_{t, t-1}^{1}+v_{t}^{1}=\frac{w_{1}}{w_{1}^{B}}\left(F_{t, t-1}^{B, 1}-\hat{A}_{t, t-1}\right)+v_{t}^{1}
$$

Thus a regression of realized changes in earnings on biased forecasts will identify $w_{1} / w_{1}^{B}$. But the first unbiased forecast is related to the first biased forecast as follows:

$$
F_{t, t-1}^{1}-\hat{A}_{t, t-1}=w_{1} S_{t, t-1}^{1}=\frac{w_{1}}{w_{1}^{B}}\left(F_{t, t-1}^{B, 1}-\hat{A}_{t, t-1}\right)
$$

So the second analyst can infer the value of the unbiased forecast. Her forecast will then be

$$
\begin{aligned}
& F_{t, t-1}^{B, 2}-\hat{A}_{t, t-1}=\left(1-w_{2}^{B}\right)\left(F_{t, t-1}^{1}-\hat{A}_{t, t-1}\right)+w_{2}^{B} S_{t, t-1}^{2} \\
& =\left(1-w_{2}^{B}\right)\left(\frac{w_{1}}{w_{1}^{B}}\left(F_{t, t-1}^{B, 1}-\hat{A}_{t, t-1}\right)\right)+w_{2}^{B}\left(A_{t}-\hat{A}_{t, t-1}\right)+w_{2}^{B} \eta_{t-1}^{2}
\end{aligned}
$$

where

$$
w_{2}^{B}=\frac{\left(1+a_{2}\right) \pi_{\eta}^{2}}{\pi_{\varepsilon}+\pi_{\eta}^{1}+\left(1+a_{2}\right) \pi_{\eta}^{2}} .
$$

The relationship between the second unbiased forecast and the biased forecasts is 


$$
F_{t, t-1}^{2}-\hat{A}_{t, t-1}=\frac{w_{2}}{w_{2}^{B}}\left(F_{t, t-1}^{B, 2}-\hat{A}_{t, t-1}\right)+\left(1-\frac{w_{2}}{w_{2}^{B}}\right)\left(\frac{w_{1}}{w_{1}^{B}}\left(F_{t, t-1}^{B, 1}-\hat{A}_{t, t-1}\right)\right)
$$

where $w_{2}=\frac{\pi_{\eta}^{2}}{\pi_{\varepsilon}+\pi_{\eta}^{1}+\pi_{\eta}^{2}}$ is the unbiased weight for the private signal of the second analyst.

In general, the $\mathrm{i}^{\text {th }}$ observed forecast will be given by

$$
F_{t, t-1}^{B, i}-\hat{A}_{t, t-1}=\left(1-w_{i}^{B}\right)\left(F_{t, t-1}^{i-1}-\hat{A}_{t, t-1}\right)+w_{i}^{B} S_{t, t-1}^{i}
$$

where

$$
w_{i}^{B}=\frac{\left(1+a_{i}\right) \pi_{\eta}^{i}}{\pi_{\varepsilon}+\sum_{j=1}^{i-1} \pi_{\eta}^{j}+\left(1+a_{i}\right) \pi_{\eta}^{i}}
$$

and

$$
F_{t, t-1}^{i-1}=\frac{w_{i-1}}{w_{i-1}^{B}}\left(F_{t, t-1}^{B, i-1}\right)+\left(1-\frac{w_{i-1}}{w_{i-1}^{B}}\right)\left(F_{t, t-1}^{i-2}\right)
$$

which are the expressions in (11) and (12) of the text.

\section{Appendix B}

This section contains technical details for the GMM estimation of the rational and cognitive bias models. The fundamental moment conditions are the same for both models, with the rational model imposing several parameter restrictions, described below. The four fundamental moment conditions, in general form, are:

$$
\begin{aligned}
& E\left[F_{t, t-1}^{B, i}-A_{t}-\mu^{i}\right]=0 \\
& E\left[\left\{F_{t, t-1}^{B, i}-A_{t}-\mu^{i}\right\}^{2}-\frac{1}{\pi_{\varepsilon}+\sum_{j=1}^{i-1} \pi_{\eta}^{j}}\right]=0 \\
& E\left[F_{t, t-1}^{i}-b_{0, i}-\left(1-w_{i}^{B}\right) F_{t, t-1}^{i-1}-w_{i}^{B} A_{t}-w_{i}^{B} k\left(F_{t-1, t-2}^{i}-A_{t-1}\right)\right]=0 \\
& E\left[\left\{F_{t, t-1}^{i}-b_{0, i}-\left(1-w_{i}^{B}\right) F_{t, t-1}^{i-1}-w_{i}^{B} A_{t}-w_{i}^{B} k\left(F_{t-1, t-2}^{i}-A_{t-1}\right)\right\}^{2}-\left(w_{i}^{B}\right)^{2} \cdot\left(\pi_{\eta}^{i}\right)^{-1}\right]=0
\end{aligned}
$$

where $\mathrm{i}=1,2, \ldots, 16$. The parameter $\mu^{i}$ measures the average forecast error for the $\mathrm{i}^{\text {th }}$ ordered forecast, thus controlling for any optimism or pessimism bias in the $\mathrm{i}^{\text {th }}$ ordered forecast. All 
other parameters are as defined in the text. Moment conditions (B.1) through (B.4) are estimated separately for each ordered forecast, yielding a total of 64 moment conditions. The first and second sets of moment conditions yield estimates of sequential forecast bias and consensus forecast precision. The third set of moment conditions represents the basic regression equation, and to obtain consistent estimates for the regression parameters, we cross-multiply each of the moment conditions in the third set by the instrument vector $Z_{t}=\left[1, F_{t, t-1}^{B, i}, A_{t}\right]$, which produces 32 additional moment conditions, for a total of 96 moment conditions. Recall that the orthogonality of $A_{t}$ with the regression error term follows from the model. The fourth set of moment conditions produces sequential estimates of private signal precision. The following parameter restriction is imposed by both the rational model and the model with overconfidence and cognitive dissonance:

$$
w_{i}^{B}=\frac{(1+a) \pi_{\eta}^{i}}{\pi_{\varepsilon}+\sum_{j=1}^{i-1} \pi_{\eta}^{j}+(1+a) \pi_{\eta}^{i}}
$$

The rational model imposes two additional restrictions:

$$
\begin{aligned}
& a=0 \\
& k=0
\end{aligned}
$$

Thus, the model with cognitive biases contains two more variables than the rational model.

\section{Estimation}

Write the set of all moment conditions as

$$
E\left[f\left(x_{t}, \boldsymbol{\theta}\right)\right]=0
$$

where $x_{t}$ represents the data and $\boldsymbol{\theta}$ the vector of parameters to be estimated. The first-stage of our GMM procedure requires the minimization of the quadratic form of the following term:

$$
g_{N}(\boldsymbol{\theta}) \equiv \frac{1}{N} \sum_{i=1}^{N} f\left(x_{t}, \boldsymbol{\theta}\right) .
$$

That is, the parameter estimates are given by:

$$
\hat{\boldsymbol{\theta}}=\arg \min \mathrm{q} \text {, where } \mathrm{q} \equiv g_{N}^{\prime}(\boldsymbol{\theta}) W g_{N}(\boldsymbol{\theta}) \text {. }
$$

As a first step, we estimate unrestricted parameters, $\hat{\theta}_{1}$ using $W=I_{N \times N}$. These initial parameter estimates are consistent but inefficient, and are used to construct the asymptotically efficient 
weight matrix $S$ (Hansen (1982) shows that the optimal weight matrix is equal to the inverse of the covariance matrix of the moment conditions. We calculate this matrix using the first-stage parameter estimates). This efficient weight matrix is then used to calculate the second-stage GMM parameter estimates reported in the paper.

The nested nature of our model allows us to directly compare the rational and biased models. Following Newey and West (1987) and Cochrane (2001), we define:

$$
D=N \cdot q_{\text {restricted }}-N \cdot q_{\text {unrestricted }}
$$

where $N$ equals the number of observations in our sample, and $q_{0}$ represents the second-stage minimized value of the GMM objective function for the restricted (rational) and unrestricted (cognitive bias) models. $D$ has an asymptotic Chi-square distribution with degrees of freedom equal to the number of parameters in the unrestricted model minus the number of parameters in the restricted model. Thus, $D \stackrel{a}{\longrightarrow} \chi_{(2)}^{2}$.

We have experimented with other GMM weighting schemes. For example, we have employed a Limited Information estimation procedure, in which we first estimate the consensus precision parameters using the first two sets of moment conditions, then use these estimates to calculate the remaining parameters using an asymptotically efficient 2-stage procedure. Other weighting schemes we have examined include estimating the cross-products of instruments times all equations in the third and fourth sets of moment conditions using the asymptotically efficient weight matrix; and estimating all moment conditions using a one-stage procedure with the identity weight matrix. The parameter estimates across the methods obviously differ to some degree, but in all instances our fundamental results are unchanged. 


\section{Footnotes}

${ }^{1}$ The theory was first expounded by Festinger (1957). It has been described as one of the most influential theories in social psychology (Jones, 1985) and has been the stimulus for a great number of experimental studies.

${ }^{2}$ The theory of cognitive dissonance has been applied in an economic context in Akerlof and Dickens (1982) and in a financial context in Goetzmann and Peles (1997).

${ }^{3}$ In the context of our model, the information content is implicitly measured by the improvement in forecast precision relative to the previously issued forecast. This approach differs from other studies that use a market-based measure of information content. For example, Gleason and Lee (2002) and Cooper, Day and Lewis (2001) study the properties of analyst forecast revisions. In those studies, each forecast's information content is measured using market-based responses (excess returns or volume) to the forecast revision.

${ }^{4}$ Because we are examining the precision of the forecasts themselves, and not the precision of the parameters used to generate the forecasts, the mean squared forecast error is calculated by dividing the sum of the squared forecast errors by the number of observations (see Greene 1997, pp. 372-373). However, the number of observations in our sample is so large that even if a loss of degrees of freedom in the regression parameters translated into a loss of degrees of freedom in the mean squared forecast error, the relative performance of the predictors would remain unchanged.

${ }^{5}$ Firms may punish analysts who issue negative or pessimistic forecasts by excluding them from conference calls (or other forms of direct contact with management), terminating correspondence, and even threatening legal or physical harm (Siconolfi 1995; Schultz 1990; Berg 1990). Michaely and Womack (1999) suggest that an analyst may issue more favorable forecasts for firms that have an underwriting relationship with the analyst's company.

${ }^{6}$ Lim (2001) develops a model in which analyst forecast bias is fully rational, because it induces firm management to provide better information to the optimistic analyst. The improved information is sufficient to decrease the analyst's mean squared forecast error.

${ }^{7}$ McNichols, O’Brien and Francis (1997) find that analysts tend to drop coverage of firms that they expect to do poorly rather than retain them and issue negative comments. This incentive not to release unfavorable forecasts truncates the left tail of the forecast distribution, producing observationally biased forecasts even when the true forecast distribution is unbiased. Other studies suggest that the observed upward bias is the result of discretionary asset write-downs (Keane and Runkle 1998) or skewed data (Abarbanell and Lehavy 2000).

${ }^{8}$ Information on forecasts is easily accessible. I/B/E/S, Zack's and First Call, the main providers of earnings forecast information, all offer real-time web-based access to forecast data.

${ }^{9}$ However we argue below that such incentives are likely to be insignificant in the context we consider.

${ }^{10}$ This would include a loss function equal to the mean squared forecast error.

${ }^{11}$ This assumes for notational simplicity that each analyst's forecast appears at the same point in the forecast order in successive quarters. We do not assume that this is the case in the empirical analysis.

${ }^{12}$ We assume that large pieces of new public information are followed by two or more simultaneous forecasts. By eliminating multiple forecast days from our regressions (though still including them in the information set of all subsequent forecasts), we aim to isolate the effect of private information on forecasts.

${ }^{13}$ Keane and Runkle (1998) find that including all earnings forecast observations in their analysis leads to rejection of the hypothesis of rational forecasts. However, after eliminating outliers they can no longer reject the rational hypothesis. 
${ }^{14}$ Bernard and Thomas (1990) show that pooled, seasonally-differenced earnings are predictable using lagged values of differenced earnings, particularly at lags 1 and 2. Clearly, earnings for some firms will be more predictable than others. Thus, we extend Bernard and Thomas (1990) by fitting separate AR(2) models for each firm.

${ }^{15}$ Results are virtually identical when we eliminate observations $+/-4$ standard deviations from the mean.

${ }^{16}$ This considerably simplifies the expression for the $\mathrm{i}^{\text {th }}$ analyst's forecast. While this could theoretically bias our estimates, we doubt this is the case for two reasons. First, since the median forecast error in our sample is zero, the lagged forecast errors of analysts $\mathrm{j}=1,2, \ldots, \mathrm{i}-1$ may tend to cancel each other out, and incorporating them individually into the $\mathrm{i}^{\text {th }}$ forecast may yield little benefit. Second, as we demonstrate below, the economic significance of the cognitive dissonance bias is fairly small, and ignoring the cognitive dissonance bias in other forecasts would likely have little effect on the $\mathrm{i}^{\text {th }}$ analyst's own forecast precision. In contrast, we also show below that the overconfidence bias is quite significant, both economically and statistically.

${ }^{17}$ In Table III, we utilize a consensus measure equal to a weighted average of all previously issued forecasts, where the weights are functions of the estimated cognitive bias parameters, as well as the estimated weights each past analyst placed on her private information. We have also estimated the table with consensus measures equal to the average of all existing forecasts; the average of the most recent two, three or four forecasts; the most recent existing forecast; and the average of all forecasts issued in the past 30 days. In all cases, the results are similar.

${ }^{18}$ Zitzewitz (2001b) does allow the analyst to make multiple forecasts within a period, and shows that the incentive to overweight private information declines with the number of forecasts made.

${ }^{19}$ Firms with negative B-M ratios are excluded from the low B-M quartile, since firms with negative B-M ratios have properties very different from firms with small, positive B-M ratios.

20 The large jump in precision from the $15^{\text {th }}$ ordered forecast the " $16^{\text {th }}+$ " forecasts occurs because the " $16^{\text {th }}+"$ category contains not only the $16^{\text {th }}$ forecasts, but all subsequent forecasts, whose precision continues to sequentially increase. The pooled precision estimates are therefore higher than the precision for the $16^{\text {th }}$ ordered forecasts alone. 


\section{Table I}

Sample Statistics for Raw and Sigma-Normalized Data

Full sample includes all one- and two-quarter-ahead quarterly earnings forecasts in the I/B/E/S Domestic Detail File over the 1993-1999 period. Actual earnings data are taken from the domestic I/B/E/S Actuals File. To be included in the full sample, a firm must have at least 12 seasonally-differenced quarterly earnings observations. Additional cumulative data filters are applied as follows: Filter A eliminates observations with Price $<\$ 5$ per share. Filter B eliminates observations from analysts with fewer than 25 total forecasts during the sample period, as well as all forecasts issued on multiple-forecast days (days on which 2 or more forecasts are issued). Filter $\mathrm{C}$ excludes forecasts made before the most recent past quarterly earnings announcement. Filter $\mathrm{D}$ eliminates forecasts more than six standard deviations from actual reported earnings, where firm-specific standard deviations are estimated by fitting an AR(2) model to actual earnings over the entire sample period. It also eliminates forecasts for which no prior forecasts exist.

\begin{tabular}{|c|c|c|c|c|c|c|c|c|c|c|c|c|}
\hline \multirow[b]{2}{*}{ Variable } & \multirow[b]{2}{*}{$\begin{array}{l}\text { Data } \\
\text { Filter }\end{array}$} & \multirow[b]{2}{*}{$\begin{array}{l}\text { N. obs in } \\
\text { sample }\end{array}$} & \multicolumn{5}{|c|}{ Panel A: Raw Data } & \multicolumn{5}{|c|}{ Panel B: Sigma-Normalized Data } \\
\hline & & & Mean & Median & $\begin{array}{l}\text { Std. } \\
\text { Dev }\end{array}$ & Min. & Max. & Mean & Median & $\begin{array}{l}\text { Std. } \\
\text { Dev }\end{array}$ & Min. & Max. \\
\hline Actual & Full & 989,967 & 0.298 & 0.235 & 1.444 & -363.650 & 125.970 & 3.784 & 2.245 & 5.506 & -10.254 & 63.321 \\
\hline \multirow[t]{4}{*}{ Earnings } & Filter A & 909,046 & 0.322 & 0.255 & 1.386 & -249.900 & 125.970 & 4.024 & 2.459 & 5.641 & -10.254 & 63.321 \\
\hline & Filter B & 624,144 & 0.323 & 0.250 & 1.574 & -249.900 & 125.970 & 3.883 & 2.372 & 5.469 & -10.254 & 63.321 \\
\hline & Filter C & 389,233 & 0.323 & 0.253 & 1.558 & -249.900 & 125.970 & 3.838 & 2.359 & 5.382 & -10.254 & 63.321 \\
\hline & Filter D & 307,532 & 0.336 & 0.268 & 1.218 & -39.000 & 125.970 & 4.013 & 2.482 & 5.519 & -10.254 & 63.076 \\
\hline Forecasted & Full & 989,967 & 0.374 & 0.250 & 36.986 & -250.000 & 36875.0 & 3.922 & 2.342 & 8.451 & -283.404 & 6384.46 \\
\hline \multirow[t]{4}{*}{ Earnings } & Filter A & 909,046 & 0.360 & 0.270 & 1.354 & -250.000 & 143.060 & 4.157 & 2.551 & 5.626 & -283.404 & 582.781 \\
\hline & Filter B & 624,144 & 0.361 & 0.270 & 1.535 & -250.000 & 143.060 & 4.014 & 2.463 & 5.489 & -283.404 & 582.781 \\
\hline & Filter C & 389,233 & 0.346 & 0.260 & 1.513 & -250.000 & 143.060 & 3.896 & 2.379 & 5.458 & -283.404 & 582.781 \\
\hline & Filter D & 307,532 & 0.356 & 0.273 & 1.184 & -11.667 & 131.050 & 4.057 & 2.500 & 5.437 & -10.928 & 61.165 \\
\hline Analyst & Full & 989,967 & 0.075 & 0.000 & 36.968 & -247.200 & 36874.3 & 0.138 & 0.000 & 6.552 & -280.230 & 6384.30 \\
\hline Forecast & Filter A & 909,046 & 0.037 & 0.000 & 0.582 & -247.200 & 218.400 & 0.132 & 0.000 & 1.297 & -280.230 & 576.953 \\
\hline \multirow[t]{3}{*}{ Error } & Filter B & 624,144 & 0.038 & 0.000 & 0.667 & -247.200 & 218.400 & 0.131 & 0.000 & 1.382 & -280.230 & 576.953 \\
\hline & Filter C & 389,233 & 0.024 & 0.000 & 0.717 & -247.200 & 218.400 & 0.059 & 0.000 & 1.469 & -280.230 & 576.953 \\
\hline & Filter D & 307,532 & 0.020 & 0.000 & 0.405 & -22.130 & 65.730 & 0.044 & 0.000 & 0.712 & -5.975 & 5.974 \\
\hline
\end{tabular}




\section{Table II \\ Regression of $i^{\text {th }}$ Analyst Forecast on Lagged Forecasts}

Table presents regression slope coefficients from a regression of the $\mathrm{i}^{\text {th }}$ observed forecast, $F_{t, t-1}$, on lagged forecast changes $F_{t, t-1}^{j}-\hat{A}_{t, t-1}, j=1,2, \ldots, i-1$ and actual time-t earnings changes, $A_{t}-\hat{A}_{t, t-1}$. Regressions include an intercept term, which is omitted for brevity. For the $8^{\text {th }}$ and later ordered forecasts, we report only the coefficients on the first seven lagged forecasts. Data reflect Filter D (see Table I). $\hat{A}_{t, t-1}$ is calculated using, and all data are normalized by, firmspecific AR(2) standard errors. White Heteroskedasticity consistent standard errors reported in parentheses.

Slope Coefficients

\begin{tabular}{|c|c|c|c|c|c|c|c|c|}
\hline $\begin{array}{c}\text { Forecast } \\
\text { order } \\
\mathrm{i} \\
\end{array}$ & $\mathrm{i}-1$ & $\mathrm{i}-2$ & $i-3$ & $\mathrm{i}-4$ & $i-5$ & $i-6$ & $\mathrm{i}-7$ & $A_{t}-\hat{A}_{t, t-1}$ \\
\hline 2 & $\begin{array}{l}0.791 \\
(0.002)\end{array}$ & & & & & & & $\begin{array}{c}0.2039 \\
(0.002)\end{array}$ \\
\hline 3 & $\begin{array}{l}0.489 \\
(0.004)\end{array}$ & $\begin{array}{l}0.353 \\
(0.004)\end{array}$ & & & & & & $\begin{array}{l}0.157 \\
(0.003)\end{array}$ \\
\hline 4 & $\begin{array}{l}0.408 \\
(0.005)\end{array}$ & $\begin{array}{l}0.236 \\
(0.005)\end{array}$ & $\begin{array}{c}0.197 \\
(0.005)\end{array}$ & & & & & $\begin{array}{l}0.158 \\
(0.003)\end{array}$ \\
\hline 5 & $\begin{array}{l}0.347 \\
(0.006)\end{array}$ & $\begin{array}{l}0.205 \\
(0.005)\end{array}$ & $\begin{array}{l}0.156 \\
(0.006)\end{array}$ & $\begin{array}{l}0.125 \\
(0.005)\end{array}$ & & & & $\begin{array}{l}0.166 \\
(0.003)\end{array}$ \\
\hline 6 & $\begin{array}{l}0.331 \\
(0.006)\end{array}$ & $\begin{array}{l}0.192 \\
(0.006)\end{array}$ & $\begin{array}{l}0.136 \\
(0.006)\end{array}$ & $\begin{array}{l}0.095 \\
(0.006)\end{array}$ & $\begin{array}{l}0.080 \\
(0.006)\end{array}$ & & & $\begin{array}{l}0.166 \\
(0.004)\end{array}$ \\
\hline 7 & $\begin{array}{l}0.330 \\
(0.007)\end{array}$ & $\begin{array}{l}0.180 \\
(0.007)\end{array}$ & $\begin{array}{l}0.145 \\
(0.007)\end{array}$ & $\begin{array}{l}0.089 \\
(0.007)\end{array}$ & $\begin{array}{l}0.046 \\
(0.007)\end{array}$ & $\begin{array}{l}0.050 \\
(0.007)\end{array}$ & & $\begin{array}{l}0.157 \\
(0.004)\end{array}$ \\
\hline 8 & $\begin{array}{c}0.281 \\
(0.008)\end{array}$ & $\begin{array}{l}0.248 \\
(0.008)\end{array}$ & $\begin{array}{c}0.114 \\
(0.007)\end{array}$ & $\begin{array}{c}0.072 \\
(0.008)\end{array}$ & $\begin{array}{l}0.044 \\
(0.008)\end{array}$ & $\begin{array}{l}0.030 \\
(0.007)\end{array}$ & $\begin{array}{l}0.044 \\
(0.007)\end{array}$ & $\begin{array}{l}0.167 \\
(0.005)\end{array}$ \\
\hline 9 & $\begin{array}{c}0.312 \\
(0.010)\end{array}$ & $\begin{array}{l}0.195 \\
(0.009)\end{array}$ & $\begin{array}{l}0.129 \\
(0.009)\end{array}$ & $\begin{array}{l}0.079 \\
(0.008)\end{array}$ & $\begin{array}{l}0.065 \\
(0.009)\end{array}$ & $\begin{array}{l}0.041 \\
(0.009)\end{array}$ & $\begin{array}{l}0.020 \\
(0.008)\end{array}$ & $\begin{array}{l}0.157 \\
(0.006)\end{array}$ \\
\hline 10 & $\begin{array}{l}0.297 \\
(0.011)\end{array}$ & $\begin{array}{l}0.184 \\
(0.011)\end{array}$ & $\begin{array}{l}0.113 \\
(0.010)\end{array}$ & $\begin{array}{l}0.099 \\
(0.011)\end{array}$ & $\begin{array}{l}0.074 \\
(0.011)\end{array}$ & $\begin{array}{l}0.037 \\
(0.010)\end{array}$ & $\begin{array}{l}0.036 \\
(0.010)\end{array}$ & $\begin{array}{l}0.161 \\
(0.007)\end{array}$ \\
\hline 11 & $\begin{array}{c}0.236 \\
(0.013)\end{array}$ & $\begin{array}{c}0.175 \\
(0.013)\end{array}$ & $\begin{array}{c}0.181 \\
(0.013)\end{array}$ & $\begin{array}{c}0.095 \\
(0.013)\end{array}$ & $\begin{array}{c}0.070 \\
(0.012)\end{array}$ & $\begin{array}{l}0.040 \\
(0.011)\end{array}$ & $\begin{array}{c}0.016 \\
(0.011)\end{array}$ & $\begin{array}{l}0.186 \\
(0.008)\end{array}$ \\
\hline 12 & $\begin{array}{l}0.237 \\
(0.015)\end{array}$ & $\begin{array}{l}0.223 \\
(0.016)\end{array}$ & $\begin{array}{l}0.113 \\
(0.016)\end{array}$ & $\begin{array}{l}0.116 \\
(0.015)\end{array}$ & $\begin{array}{l}0.100 \\
(0.015)\end{array}$ & $\begin{array}{l}0.057 \\
(0.015)\end{array}$ & $\begin{array}{l}0.005 \\
(0.012)\end{array}$ & $\begin{array}{l}0.147 \\
(0.009)\end{array}$ \\
\hline 13 & $\begin{array}{l}0.227 \\
(0.016)\end{array}$ & $\begin{array}{l}0.159 \\
(0.016)\end{array}$ & $\begin{array}{l}0.154 \\
(0.017)\end{array}$ & $\begin{array}{l}0.134 \\
(0.017)\end{array}$ & $\begin{array}{l}0.050 \\
(0.016)\end{array}$ & $\begin{array}{l}0.081 \\
(0.015)\end{array}$ & $\begin{array}{l}0.023 \\
(0.014)\end{array}$ & $\begin{array}{l}0.171 \\
(0.010)\end{array}$ \\
\hline 14 & $\begin{array}{l}0.187 \\
(0.002)\end{array}$ & $\begin{array}{l}0.310 \\
(0.018)\end{array}$ & $\begin{array}{l}0.110 \\
(0.019)\end{array}$ & $\begin{array}{l}0.091 \\
(0.020)\end{array}$ & $\begin{array}{l}0.075 \\
(0.019)\end{array}$ & $\begin{array}{l}0.074 \\
(0.019)\end{array}$ & $\begin{array}{l}0.018 \\
(0.018)\end{array}$ & $\begin{array}{l}0.133 \\
(0.013)\end{array}$ \\
\hline 15 & $\begin{array}{l}0.179 \\
(0.024)\end{array}$ & $\begin{array}{l}0.219 \\
(0.027)\end{array}$ & $\begin{array}{l}0.089 \\
(0.022)\end{array}$ & $\begin{array}{l}0.149 \\
(0.021)\end{array}$ & $\begin{array}{l}0.119 \\
(0.023)\end{array}$ & $\begin{array}{l}0.229 \\
(0.020)\end{array}$ & $\begin{array}{c}0.072 \\
(0.020)\end{array}$ & $\begin{array}{l}0.148 \\
(0.015)\end{array}$ \\
\hline $16+$ & $\begin{array}{c}0.192 \\
(0.017)\end{array}$ & $\begin{array}{l}0.113 \\
(0.016)\end{array}$ & $\begin{array}{l}0.189 \\
(0.016)\end{array}$ & $\begin{array}{l}0.119 \\
(0.016)\end{array}$ & $\begin{array}{l}0.139 \\
(0.015)\end{array}$ & $\begin{array}{l}0.034 \\
(0.015)\end{array}$ & $\begin{array}{l}0.071 \\
(0.014)\end{array}$ & $\begin{array}{l}0.142 \\
(0.011)\end{array}$ \\
\hline
\end{tabular}




\section{Table III}

\section{GMM Estimation and Model Comparison}

Regressions below estimate (i) the rational model equation $F_{t, t-1}^{i}=b_{0, i}+\left(1-w_{i}\right) \bar{F}_{t, t-1}^{i}+w_{i} A_{t}+w_{i} \eta_{t-1}^{i}$, and (ii) the equation for the model with cognitive bias $F_{t, t-1}^{B, i}=b_{0, i}+\left(1-w_{i}^{B}\right) \bar{F}_{t, t-1}^{B, i}+w_{i}^{B} A_{t}+w_{i}^{B} k\left(F_{t-1, t-2}^{B, i}-A_{t-1}\right)+w_{i}^{B} \eta_{t-1}^{i}$ where $F_{t, t-1}^{i}\left(F_{t, t-1}^{B, i}\right)$ is the $\mathrm{i}^{\text {th }}$ sequential analyst forecast, $\bar{F}_{t, t-1}^{i}\left(\bar{F}_{t, t-1}^{B, i}\right)$ is the consensus defined as a weighted average of all previously issued forecasts, where the weights are functions of the estimated cognitive bias parameters, as well as the estimated weights each past analyst placed on her private information., and $A_{t}$ is the actual quarterly earnings reported at time $t$. Data reflect Filter D (see Table I). All data are normalized by firm-specific AR(2) standard errors. See text and Appendix for details of GMM estimation. The Newey-West D-statistic equals $\mathrm{N}$ times the minimized value of the GMM objective function in the restricted (rational) model, minus the same statistic from the unrestricted model. This statistic has an asymptotic chi-squared distribution with 2 degrees of freedom. GMM standard errors are reported in parentheses.

\begin{tabular}{|c|c|c|c|c|c|c|c|c|}
\hline \multicolumn{5}{|c|}{ Rational Model } & \multicolumn{4}{|c|}{ Model with Cognitive Bias } \\
\hline $\begin{array}{c}\text { Forecast } \\
\text { order }\end{array}$ & Constant & $\begin{array}{l}\text { Consensus } \\
\text { precision }\end{array}$ & $\begin{array}{l}\text { Private } \\
\text { signal } \\
\text { precision }\end{array}$ & Implied $w_{i}$ & Constant & $\begin{array}{l}\text { Consensus } \\
\text { precision }\end{array}$ & $\begin{array}{l}\text { Private } \\
\text { signal } \\
\text { precision }\end{array}$ & Implied $w_{i}^{B}$ \\
\hline 1 & $\begin{array}{l}0.106 \\
(0.005)\end{array}$ & $\begin{array}{l}1.512 \\
(0.023)\end{array}$ & $\begin{array}{l}0.417 \\
(0.015)\end{array}$ & 0.22 & $\begin{array}{l}0.112 \\
(0.004)\end{array}$ & $\begin{array}{l}1.528 \\
(0.020)\end{array}$ & $\begin{array}{l}0.168 \\
(0.007)\end{array}$ & 0.18 \\
\hline 2 & $\begin{array}{l}0.089 \\
(0.004)\end{array}$ & $\begin{array}{l}1.813 \\
(0.038)\end{array}$ & $\begin{array}{l}0.428 \\
(0.025)\end{array}$ & 0.19 & $\begin{array}{l}0.099 \\
(0.004)\end{array}$ & $\begin{array}{l}1.706 \\
(0.023)\end{array}$ & $\begin{array}{l}0.166 \\
(0.008)\end{array}$ & 0.16 \\
\hline 3 & $\begin{array}{l}0.076 \\
(0.004)\end{array}$ & $\begin{array}{l}2.049 \\
(0.032)\end{array}$ & $\begin{array}{l}0.397 \\
(0.017)\end{array}$ & 0.16 & $\begin{array}{l}0.087 \\
(0.004)\end{array}$ & $\begin{array}{l}1.825 \\
(0.022)\end{array}$ & $\begin{array}{l}0.180 \\
(0.007)\end{array}$ & 0.16 \\
\hline 4 & $\begin{array}{l}0.028 \\
(0.004)\end{array}$ & $\begin{array}{l}2.215 \\
(0.040)\end{array}$ & $\begin{array}{l}0.805 \\
(0.044)\end{array}$ & 0.27 & $\begin{array}{l}0.035 \\
(0.003)\end{array}$ & $\begin{array}{l}1.911 \\
(0.023)\end{array}$ & $\begin{array}{l}0.217 \\
(0.010)\end{array}$ & 0.18 \\
\hline 5 & $\begin{array}{l}0.052 \\
(0.004)\end{array}$ & $\begin{array}{l}2.356 \\
(0.047)\end{array}$ & $\begin{array}{l}0.523 \\
(0.026)\end{array}$ & 0.18 & $\begin{array}{l}0.060 \\
(0.004)\end{array}$ & $\begin{array}{l}2.027 \\
(0.029)\end{array}$ & $\begin{array}{l}0.222 \\
(0.010)\end{array}$ & 0.18 \\
\hline 6 & $\begin{array}{l}0.043 \\
(0.004)\end{array}$ & $\begin{array}{l}2.565 \\
(0.057)\end{array}$ & $\begin{array}{l}0.601 \\
(0.032)\end{array}$ & 0.19 & $\begin{array}{l}0.047 \\
(0.004)\end{array}$ & $\begin{array}{l}2.195 \\
(0.035)\end{array}$ & $\begin{array}{l}0.243 \\
(0.012)\end{array}$ & 0.18 \\
\hline 7 & $\begin{array}{l}0.035 \\
(0.004)\end{array}$ & $\begin{array}{l}2.902 \\
(0.080)\end{array}$ & $\begin{array}{l}0.574 \\
(0.041)\end{array}$ & 0.17 & $\begin{array}{l}0.036 \\
(0.004)\end{array}$ & $\begin{array}{l}2.372 \\
(0.044)\end{array}$ & $\begin{array}{l}0.264 \\
(0.017)\end{array}$ & 0.18 \\
\hline 8 & $\begin{array}{l}-0.009 \\
(0.004)\end{array}$ & $\begin{array}{l}3.057 \\
(0.092)\end{array}$ & $\begin{array}{l}1.487 \\
(0.133)\end{array}$ & 0.33 & $\begin{array}{l}-0.011 \\
(0.004)\end{array}$ & $\begin{array}{l}2.496 \\
(0.046)\end{array}$ & $\begin{array}{l}0.319 \\
(0.022)\end{array}$ & 0.20 \\
\hline 9 & $\begin{array}{l}-0.026 \\
(0.004)\end{array}$ & $\begin{array}{l}3.168 \\
(0.109)\end{array}$ & $\begin{array}{l}1.430 \\
(0.149)\end{array}$ & 0.31 & $\begin{array}{l}-0.027 \\
(0.004)\end{array}$ & $\begin{array}{l}2.565 \\
(0.052)\end{array}$ & $\begin{array}{l}0.322 \\
(0.027)\end{array}$ & 0.20 \\
\hline 10 & $\begin{array}{l}-0.033 \\
(0.004)\end{array}$ & $\begin{array}{l}3.513 \\
(0.140)\end{array}$ & $\begin{array}{l}1.864 \\
(0.233)\end{array}$ & 0.35 & $\begin{array}{l}-0.036 \\
(0.005)\end{array}$ & $\begin{array}{l}2.845 \\
(0.065)\end{array}$ & $\begin{array}{l}0.376 \\
(0.034)\end{array}$ & 0.20 \\
\hline 11 & $\begin{array}{l}-0.046 \\
(0.005)\end{array}$ & $\begin{array}{l}3.870 \\
(0.181)\end{array}$ & $\begin{array}{l}2.225 \\
(0.288)\end{array}$ & 0.37 & $\begin{array}{l}-0.050 \\
(0.006)\end{array}$ & $\begin{array}{l}3.171 \\
(0.094)\end{array}$ & $\begin{array}{l}0.565 \\
(0.059)\end{array}$ & 0.26 \\
\hline 12 & $\begin{array}{l}-0.052 \\
(0.006)\end{array}$ & $\begin{array}{l}4.142 \\
(0.236)\end{array}$ & $\begin{array}{l}1.763 \\
(0.283)\end{array}$ & 0.30 & $\begin{array}{l}-0.054 \\
(0.006)\end{array}$ & $\begin{array}{l}3.354 \\
(0.118)\end{array}$ & $\begin{array}{l}0.495 \\
(0.066)\end{array}$ & 0.22 \\
\hline 13 & $\begin{array}{l}-0.064 \\
(0.007)\end{array}$ & $\begin{array}{l}4.509 \\
(0.278)\end{array}$ & $\begin{array}{l}2.279 \\
(0.384)\end{array}$ & 0.34 & $\begin{array}{l}-0.067 \\
(0.007)\end{array}$ & $\begin{array}{l}3.737 \\
(0.161)\end{array}$ & $\begin{array}{l}0.648 \\
(0.091)\end{array}$ & 0.25 \\
\hline 14 & $\begin{array}{l}-0.074 \\
(0.008)\end{array}$ & $\begin{array}{l}4.723 \\
(0.329)\end{array}$ & $\begin{array}{l}2.380 \\
(0.491)\end{array}$ & 0.34 & $\begin{array}{l}-0.080 \\
(0.007)\end{array}$ & $\begin{array}{l}4.135 \\
(0.221)\end{array}$ & $\begin{array}{l}0.755 \\
(0.145)\end{array}$ & 0.26 \\
\hline 15 & $\begin{array}{l}-0.084 \\
(0.010)\end{array}$ & $\begin{array}{l}5.517 \\
(0.472)\end{array}$ & $\begin{array}{l}2.607 \\
(0.592)\end{array}$ & 0.32 & $\begin{array}{l}-0.095 \\
(0.008)\end{array}$ & $\begin{array}{l}4.696 \\
0.0311\end{array}$ & $\begin{array}{l}0.881 \\
(0.189)\end{array}$ & 0.27 \\
\hline $16+$ & $\begin{array}{l}-0.010 \\
(0.010)\end{array}$ & $\begin{array}{l}6.108 \\
(0.892)\end{array}$ & $\begin{array}{l}3.429 \\
(1.24)\end{array}$ & 0.36 & $\begin{array}{l}-0.115 \\
(0.009)\end{array}$ & $\begin{array}{l}5.138 \\
(0.538)\end{array}$ & $\begin{array}{l}1.090 \\
(0.325)\end{array}$ & 0.29 \\
\hline & $\begin{array}{c}\mathrm{D} \\
\text { statistic }\end{array}$ & $\begin{array}{c}1,713.43 \\
(\mathrm{p}-\mathrm{val} \\
\left.<10^{-20}\right)\end{array}$ & & & $\begin{array}{l}\text { Cognitive } \\
\text { bias } \\
\text { parameters }\end{array}$ & & & \\
\hline & & & & & $a$ & $\begin{array}{l}0.937 \\
(0.027)\end{array}$ & & \\
\hline & & & & & $k$ & $\begin{array}{c}0.079 \\
(0.0073)\end{array}$ & & \\
\hline
\end{tabular}




\section{Table IV \\ GMM Estimation of Model with Cognitive Biases High and Low Book-to-Market Firms}

Each year $t$, firms are divided into high, low and medium B-M categories based on the cross-sectional distribution of B-M ratios as of the previous fiscal year-end $(t-1)$. Following Fama and French (1992), we include a six-month lag between the previous fiscal year-end and our forecasts. Thus, forecasts issued between July of year $t$ and June 30 of year $t+1$ are sorted according to the B-M ratio as of the previous fiscal year-end $(t-1)$. For instance, using the 1993 fiscal-year-end B$\mathrm{M}$ ratios for each firm, we calculate the cross-sectional distribution of these ratios, and group firms according to their relative position. All forecasts issued between 7/1/94 and 6/30/95 are then assigned to the appropriate subsample based on the firm's B-M ratio as of 1993 year end. This process is repeated for each year in the sample. B-M data are obtained from the Compustat Industrials file, and equal the book value of equity (items 60) divided by the market value of equity (item 24 times item 25). The model is estimated separately for each group. The model and estimation procedure are as described in the notes to Table II. GMM standard errors are reported in parentheses under coefficient estimates.

\begin{tabular}{|c|c|c|c|c|c|c|}
\hline \multirow{4}{*}{$\begin{array}{l}\text { Forecast } \\
\text { Order }\end{array}$} & \multicolumn{2}{|c|}{$\begin{array}{c}\text { Low Book-to-Market } \\
\text { Firms }\end{array}$} & \multicolumn{2}{|c|}{$\begin{array}{l}\text { Medium Book-to- } \\
\text { Market Firms }\end{array}$} & \multicolumn{2}{|c|}{$\begin{array}{c}\text { High Book-to-Market } \\
\text { Firms }\end{array}$} \\
\hline & & Private & & Private & & Private \\
\hline & Consensus & Signal & Consensus & Signal & Consensus & Signal \\
\hline & Precision & Precision & Precision & Precision & Precision & Precision \\
\hline \multirow[t]{2}{*}{2} & 1.726 & 0.170 & 1.685 & 1.685 & 1.719 & 0.174 \\
\hline & $(0.038)$ & $(0.012)$ & $(0.033)$ & $(0.011)$ & $(0.057)$ & $(0.017)$ \\
\hline \multirow[t]{2}{*}{3} & 1.815 & 0.175 & 1.853 & 1.852 & 1.803 & 0.178 \\
\hline & $(0.042)$ & $(0.012)$ & $(0.030)$ & $(0.010)$ & $(0.066)$ & $(0.018)$ \\
\hline \multirow[t]{2}{*}{4} & 1.879 & 0.193 & 1.951 & 1.951 & 1.918 & 0.248 \\
\hline & $(0.042)$ & $(0.017)$ & $(0.033)$ & $(0.015)$ & $(0.083)$ & $(0.035)$ \\
\hline \multirow[t]{2}{*}{5} & 1.854 & 0.208 & 2.107 & 2.107 & 2.175 & 0.280 \\
\hline & $(0.051)$ & $(0.018)$ & $(0.039)$ & $(0.014)$ & $(0.094)$ & $(0.036)$ \\
\hline \multirow[t]{2}{*}{6} & 2.007 & 0.192 & 2.294 & 2.294 & 2.314 & 0.285 \\
\hline & $(0.061)$ & $(0.018)$ & $(0.050)$ & $(0.017)$ & $(0.119)$ & $(0.040)$ \\
\hline \multirow[t]{2}{*}{7} & 2.082 & 0.197 & 2.475 & 2.475 & 2.701 & 0.316 \\
\hline & $(0.072)$ & $(0.021)$ & $(0.062)$ & $(0.021)$ & $(0.163)$ & $(0.051)$ \\
\hline \multirow[t]{2}{*}{8} & 2.114 & 0.220 & 2.690 & 2.691 & 2.687 & 0.327 \\
\hline & $(0.068)$ & $(0.026)$ & $(0.070)$ & $(0.034)$ & $(0.184)$ & $(0.061)$ \\
\hline \multirow[t]{2}{*}{9} & 2.038 & 0.201 & 2.738 & 2.739 & 3.069 & 0.443 \\
\hline & $(0.070)$ & $(0.026)$ & $(0.075)$ & $(0.043)$ & $(0.227)$ & $(0.083)$ \\
\hline \multirow[t]{2}{*}{10} & 2.398 & 0.305 & 3.082 & 3.082 & 3.170 & 0.465 \\
\hline & $(0.102)$ & $(0.043)$ & $(0.091)$ & $(0.053)$ & $(0.308)$ & $(0.112)$ \\
\hline \multirow[t]{2}{*}{11} & 2.589 & 0.443 & 3.344 & 3.344 & 4.007 & 0.866 \\
\hline & $(0.145)$ & $(0.078)$ & $(0.117)$ & $(0.079)$ & $(0.446)$ & $(0.225)$ \\
\hline \multirow[t]{2}{*}{12} & 3.090 & 0.470 & 3.469 & 3.469 & 3.440 & 0.732 \\
\hline & $(0.198)$ & $(0.092)$ & $(0.147)$ & $(0.069)$ & $(0.435)$ & $(0.284)$ \\
\hline \multirow[t]{2}{*}{13} & 3.120 & 0.464 & 4.086 & 4.086 & 4.228 & 1.381 \\
\hline & $(0.224)$ & $(0.092)$ & $(0.237)$ & $(0.107)$ & $(0.628)$ & $(0.385)$ \\
\hline \multirow[t]{2}{*}{14} & 3.844 & 0.568 & 4.045 & 4.045 & 5.505 & 1.016 \\
\hline & $(0.373)$ & $(0.220)$ & $(0.285)$ & $(0.122)$ & $(0.990)$ & $(0.505)$ \\
\hline \multirow[t]{2}{*}{15} & 3.991 & 0.984 & 4.857 & 4.827 & 5.993 & 0.997 \\
\hline & $(0.495)$ & $(0.399)$ & $(0.447)$ & $(0.251)$ & $(1.301)$ & $(0.539)$ \\
\hline \multirow[t]{2}{*}{$16+$} & 3.696 & 0.814 & 5.781 & 5.780 & 10.678 & 8.075 \\
\hline & (1.131) & $(0.604)$ & $(0.604)$ & $(0.411)$ & $(2.220)$ & (3.447) \\
\hline \multirow{3}{*}{\multicolumn{7}{|c|}{$\begin{array}{l}\text { Cognitive } \\
\text { Bias } \\
\text { Parameters } \\
\end{array}$}} \\
\hline & & & & & & \\
\hline & & & & & & \\
\hline$a$ & $\begin{array}{l}1.040 \\
(0.046)\end{array}$ & & $\begin{array}{l}0.908 \\
(0.035)\end{array}$ & & $\begin{array}{l}0.752 \\
(0.050)\end{array}$ & \\
\hline \multirow{2}{*}{$k$} & 0.103 & & 0.074 & & 0.028 & \\
\hline & $(0.014)$ & & $(0.009)$ & & $(0.015)$ & \\
\hline \multicolumn{7}{|l|}{ Avg. B-M } \\
\hline ratio & 0.139 & & 0.465 & & 0.962 & \\
\hline
\end{tabular}




\section{Table V \\ Full-Information GMM Estimation of Model with Cognitive Biases Positive and Negative Lagged Forecast Error}

Following Easterwood and Nutt (1999), we use the distribution of lagged errors to partition the sample into quartiles based upon the sign and magnitude of the lagged error. Lagged forecast error is defined as lagged forecast minus lagged actual earnings. We label the top quartile of observations "High Positive Lagged Error", the middle two quartiles "Low Lagged Error", and the bottom quartile "High Negative Lagged Error". The model is estimated separately for each group. The model and estimation procedure are as described in the notes to Table II. GMM standard errors are reported in parentheses under coefficient estimates.

\begin{tabular}{|c|c|c|c|c|c|c|}
\hline & \multicolumn{2}{|c|}{$\begin{array}{c}\text { High Positive Lagged } \\
\text { Error }\end{array}$} & \multicolumn{2}{|c|}{ Low Lagged Error } & \multicolumn{2}{|c|}{$\begin{array}{c}\text { High Negative Lagged } \\
\text { Error }\end{array}$} \\
\hline \multirow{3}{*}{$\begin{array}{l}\text { Forecast } \\
\text { Order }\end{array}$} & & Private & & Private & & Private \\
\hline & Consensus & Signal & Consensus & Signal & Consensus & Signal \\
\hline & Precision & Precision & Precision & Precision & Precision & Precision \\
\hline \multirow[t]{2}{*}{2} & 1.194 & 0.108 & 2.460 & 0.240 & 1.804 & 0.182 \\
\hline & $(0.033)$ & $(0.008)$ & $(0.053)$ & $(0.014)$ & $(0.042)$ & $(0.012)$ \\
\hline \multirow[t]{2}{*}{3} & 1.365 & 0.102 & 2.539 & 0.280 & 1.892 & 0.174 \\
\hline & $(0.031)$ & $(0.008)$ & $(0.061)$ & $(0.018)$ & $(0.051)$ & $(0.013)$ \\
\hline \multirow[t]{2}{*}{4} & 1.404 & 0.094 & 2.646 & 0.343 & 2.138 & 0.285 \\
\hline & $(0.035)$ & $(0.009)$ & $(0.071)$ & $(0.026)$ & $(0.062)$ & $(0.025)$ \\
\hline \multirow[t]{2}{*}{5} & 1.546 & 0.121 & 2.849 & 0.375 & 2.199 & 0.244 \\
\hline & $(0.046)$ & $(0.012)$ & $(0.086)$ & $(0.028)$ & $(0.074)$ & $(0.020)$ \\
\hline \multirow[t]{2}{*}{6} & 1.625 & 0.132 & 3.037 & 0.389 & 2.450 & 0.298 \\
\hline & $(0.054)$ & $(0.013)$ & $(0.106)$ & $(0.030)$ & $(0.091)$ & $(0.028)$ \\
\hline \multirow[t]{2}{*}{7} & 1.706 & 0.137 & 3.324 & 0.469 & 2.790 & 0.284 \\
\hline & $(0.061)$ & $(0.017)$ & $(0.128)$ & $(0.044)$ & $(0.115)$ & $(0.035)$ \\
\hline \multirow[t]{2}{*}{8} & 1.759 & 0.135 & 3.799 & 0.663 & 2.944 & 0.503 \\
\hline & $(0.068)$ & $(0.016)$ & $(0.177)$ & $(0.078)$ & $(0.147)$ & $(0.074)$ \\
\hline \multirow[t]{2}{*}{9} & 1.771 & 0.123 & 3.812 & 0.580 & 3.150 & 0.451 \\
\hline & $(0.074)$ & $(0.014)$ & $(0.208)$ & $(0.079)$ & $(0.183)$ & $(0.077)$ \\
\hline \multirow[t]{2}{*}{10} & 1.820 & 0.139 & 4.205 & 0.613 & 3.600 & 0.594 \\
\hline & $(0.083)$ & $(0.019)$ & $(0.249)$ & $(0.100)$ & $(0.225)$ & (0.105) \\
\hline \multirow[t]{2}{*}{11} & 2.010 & 0.225 & 4.487 & 0.792 & 3.910 & 0.871 \\
\hline & $(0.111)$ & $(0.041)$ & $(0.307)$ & $(0.138)$ & $(0.261)$ & (0.153) \\
\hline \multirow[t]{2}{*}{12} & 2.480 & 0.188 & 4.163 & 0.571 & 4.171 & 0.818 \\
\hline & $(0.192)$ & $(0.050)$ & $(0.325)$ & (0.109) & $(0.394)$ & (0.191) \\
\hline \multirow[t]{2}{*}{13} & 2.479 & 0.191 & 5.105 & 1.161 & 4.592 & 0.721 \\
\hline & $(0.209)$ & $(0.045)$ & $(0.414)$ & $(0.241)$ & $(0.419)$ & $(0.172)$ \\
\hline \multirow[t]{2}{*}{14} & 2.348 & 0.149 & 5.759 & 1.076 & 4.780 & 0.834 \\
\hline & $(0.226)$ & $(0.046)$ & $(0.500)$ & $(0.227)$ & $(0.481)$ & $(0.237)$ \\
\hline \multirow[t]{2}{*}{15} & 2.553 & 0.182 & 6.879 & 1.093 & 4.551 & 0.887 \\
\hline & $(0.241)$ & $(0.048)$ & $(0.782)$ & $(0.324)$ & $(0.591)$ & $(0.305)$ \\
\hline \multirow[t]{2}{*}{$16+$} & 3.363 & 0.331 & 6.752 & 1.372 & 3.993 & 0.700 \\
\hline & $(0.282)$ & $(0.080)$ & (0.995) & $(0.462)$ & $(0.858)$ & $(0.344)$ \\
\hline \multirow{3}{*}{\multicolumn{7}{|c|}{$\begin{array}{c}\text { Cognitive } \\
\text { Bias } \\
\text { Parameters } \\
\end{array}$}} \\
\hline & & & & & & \\
\hline & & & & & & \\
\hline \multirow{2}{*}{$a$} & 1.229 & & 0.777 & & 1.280 & \\
\hline & $(0.047)$ & & $(0.033)$ & & $(0.056)$ & \\
\hline \multirow[t]{2}{*}{$k$} & 0.008 & & 0.202 & & 0.071 & \\
\hline & $(0.011)$ & & $(0.075)$ & & $(0.016)$ & \\
\hline \multicolumn{7}{|l|}{ Mean Forecast } \\
\hline Error & 0.864 & & -0.053 & & -0.887 & \\
\hline
\end{tabular}




\section{Table VI \\ GMM Estimation of Model with Cognitive Biases Annual I/B/E/S Earnings Forecasts - United States and Japan}

Parameter estimates are obtained by estimating the equation for the model with cognitive bias $F_{t, t-1}^{B, i}=b_{0, i}+\left(1-w_{i}^{B}\right) \bar{F}_{t, t-1}^{B, i}+w_{i}^{B} A_{t}+w_{i}^{B} k\left(F_{t-1, t-2}^{B, i}-A_{t-1}\right)+w_{i}^{B} \eta_{t-1}^{i}$ where $F_{t, t-1}^{B, i}$ is the $\mathrm{i}^{\text {th }}$ sequential analyst forecast, $\bar{F}_{t, t-1}^{B, i}$ is the consensus, equal to a weighted average of past forecasts, as specified in section 3 of the paper, and $A_{t}$ is the actual annual earnings reported at time $t$. Data reflect Filter D (see Table I). All data are normalized by firm-specific standard errors. See text and Appendix for details of GMM estimation.

\begin{tabular}{|c|c|c|c|c|}
\hline \multirow[b]{2}{*}{$\begin{array}{l}\text { Forecast } \\
\text { Order }\end{array}$} & \multicolumn{2}{|c|}{ United States } & \multicolumn{2}{|c|}{ Japan } \\
\hline & $\begin{array}{l}\text { Consensus } \\
\text { Precision }\end{array}$ & $\begin{array}{l}\text { Private Signal } \\
\text { Precision }\end{array}$ & $\begin{array}{c}\text { Consensus } \\
\text { Precision } \\
\end{array}$ & $\begin{array}{c}\text { Private Signa } \\
\text { Precision }\end{array}$ \\
\hline 2 & $\begin{array}{l}3.025 \\
(0.139)\end{array}$ & $\begin{array}{l}0.466 \\
(0.058)\end{array}$ & $\begin{array}{l}2.741 \\
(0.183)\end{array}$ & $\begin{array}{l}0.218 \\
(0.045)\end{array}$ \\
\hline 3 & $\begin{array}{l}3.481 \\
(0.255)\end{array}$ & $\begin{array}{l}0.663 \\
(0.080)\end{array}$ & $\begin{array}{l}3.101 \\
(0.247)\end{array}$ & $\begin{array}{l}0.288 \\
(0.068)\end{array}$ \\
\hline 4 & $\begin{array}{l}4.834 \\
(0.506)\end{array}$ & $\begin{array}{l}1.767 \\
(0.266)\end{array}$ & $\begin{array}{l}3.739 \\
(0.290)\end{array}$ & $\begin{array}{l}0.313 \\
(0.079)\end{array}$ \\
\hline 5 & $\begin{array}{l}3.216 \\
(0.282)\end{array}$ & $\begin{array}{l}0.651 \\
(0.108)\end{array}$ & $\begin{array}{l}3.991 \\
(0.367)\end{array}$ & $\begin{array}{l}0.333 \\
(0.094)\end{array}$ \\
\hline 6 & $\begin{array}{l}4.475 \\
(0.253)\end{array}$ & $\begin{array}{l}0.829 \\
(0.114)\end{array}$ & $\begin{array}{l}4.652 \\
(0.417)\end{array}$ & $\begin{array}{l}0.548 \\
(0.159)\end{array}$ \\
\hline 7 & $\begin{array}{l}4.582 \\
(0.324)\end{array}$ & $\begin{array}{l}0.662 \\
(0.123)\end{array}$ & $\begin{array}{l}4.885 \\
(0.539)\end{array}$ & $\begin{array}{l}0.441 \\
(0.143)\end{array}$ \\
\hline 8 & $\begin{array}{l}5.541 \\
(0.332)\end{array}$ & $\begin{array}{l}1.191 \\
(0.237)\end{array}$ & $\begin{array}{l}5.322 \\
(0.771)\end{array}$ & $\begin{array}{l}0.870 \\
(0.378)\end{array}$ \\
\hline 9 & $\begin{array}{l}5.055 \\
(0.740)\end{array}$ & $\begin{array}{l}2.185 \\
(0.406)\end{array}$ & $\begin{array}{l}6.457 \\
(0.935)\end{array}$ & $\begin{array}{l}0.703 \\
(0.254)\end{array}$ \\
\hline 10 & $\begin{array}{l}5.678 \\
(0.623)\end{array}$ & $\begin{array}{l}1.773 \\
(0.400)\end{array}$ & $\begin{array}{l}4.713 \\
(0.822)\end{array}$ & $\begin{array}{l}0.417 \\
(0.240)\end{array}$ \\
\hline 11 & $\begin{array}{l}6.015 \\
(0.614)\end{array}$ & $\begin{array}{l}1.626 \\
(0.373)\end{array}$ & $\begin{array}{l}5.254 \\
(1.258)\end{array}$ & $\begin{array}{l}0.563 \\
(0.340)\end{array}$ \\
\hline 12 & $\begin{array}{l}6.369 \\
(0.597)\end{array}$ & $\begin{array}{l}1.813 \\
(0.496)\end{array}$ & $\begin{array}{l}6.052 \\
(0.809)\end{array}$ & $\begin{array}{l}1.069 \\
(0.435)\end{array}$ \\
\hline 13 & $\begin{array}{l}6.632 \\
(0.687)\end{array}$ & $\begin{array}{l}2.305 \\
(0.455)\end{array}$ & $\begin{array}{l}11.911 \\
(2.911)\end{array}$ & $\begin{array}{l}5.054 \\
(2.382)\end{array}$ \\
\hline 14 & $\begin{array}{l}7.511 \\
(0.591)\end{array}$ & $\begin{array}{l}1.628 \\
(0.414)\end{array}$ & $\begin{array}{l}7.445 \\
(1.483)\end{array}$ & $\begin{array}{l}0.481 \\
(0.132)\end{array}$ \\
\hline 15 & $\begin{array}{l}7.146 \\
(0.765)\end{array}$ & $\begin{array}{l}1.883 \\
(0.588)\end{array}$ & $\begin{array}{l}9.580 \\
(1.674)\end{array}$ & $\begin{array}{l}1.026 \\
(0.548)\end{array}$ \\
\hline $16+$ & $\begin{array}{l}8.063 \\
(0.740)\end{array}$ & $\begin{array}{l}2.436 \\
(0.529)\end{array}$ & $\begin{array}{c}10.902 \\
(1.427)\end{array}$ & $\begin{array}{l}1.465 \\
(0.351)\end{array}$ \\
\hline \multicolumn{5}{|l|}{$\begin{array}{c}\text { Cognitive } \\
\text { Bias } \\
\text { Parameters } \\
\end{array}$} \\
\hline$a$ & $\begin{array}{l}1.141 \\
(0.065)\end{array}$ & & $\begin{array}{l}1.575 \\
(0.147)\end{array}$ & \\
\hline$k$ & $\begin{array}{l}0.024 \\
(0.014)\end{array}$ & & $\begin{array}{l}0.038 \\
(0.036)\end{array}$ & \\
\hline Num. Obs. & 148,244 & & 11,672 & \\
\hline
\end{tabular}




\section{Forecast Precision by Forecast Order}

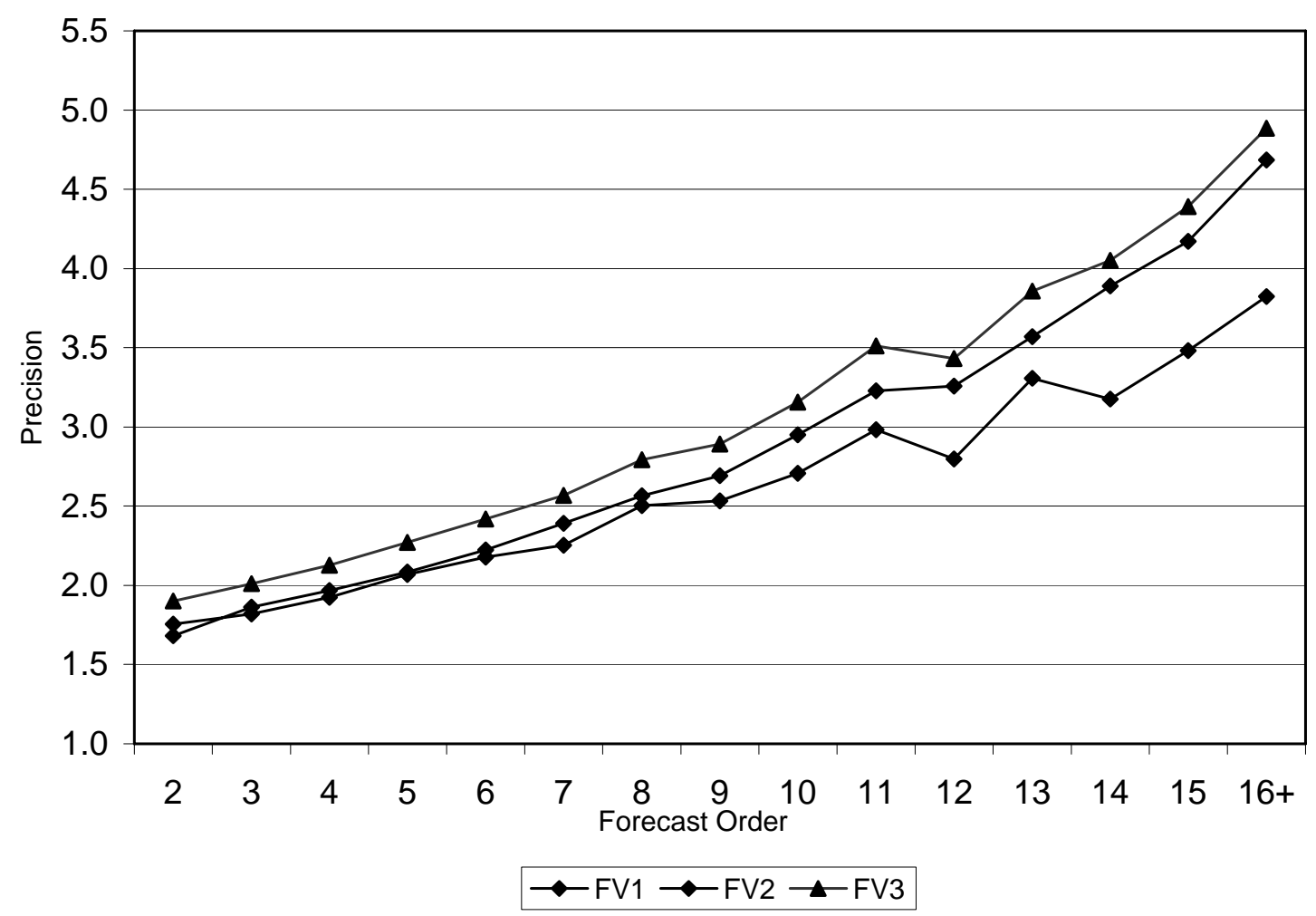

\section{Figure 1: Forecast Precision by Forecast Order}

Figure plots the forecast precision for three forecasting variables of actual time t earnings. The forecasting variables are labeled $F V_{t, t-1}^{1}$ through $F V_{t, t-1}^{3}$. The current (i ${ }^{\text {th }}$ ) analyst's actual forecast is labeled $F V_{t, t-1}^{1} . \quad F V_{t, t-1}^{2}$ is generated by regressing actual earnings on observable lagged forecasts, $\left.F_{t, t-1}^{j}\right|_{j=1} ^{i-1}$. $\quad F V_{t, t-1}^{3}$ is generated by regressing actual earnings on observable lagged forecasts, $\left.F_{t, t-1}^{j}\right|_{j=1} ^{i-1}$, as well as the current $\left(\mathrm{i}^{\mathrm{th}}\right)$ analyst's actual forecast. Forecast precision is equal to the inverse sample mean-squared forecast error for each ordered forecast. Forecasting parameters are re-estimated each quarter, using all earnings data from previous quarters. Any difference in forecast precision between $F V_{t, t-1}^{1}$ and $F V_{t, t-1}^{3}$ is due to mis-weighting of information contained in the current and lagged forecasts. 


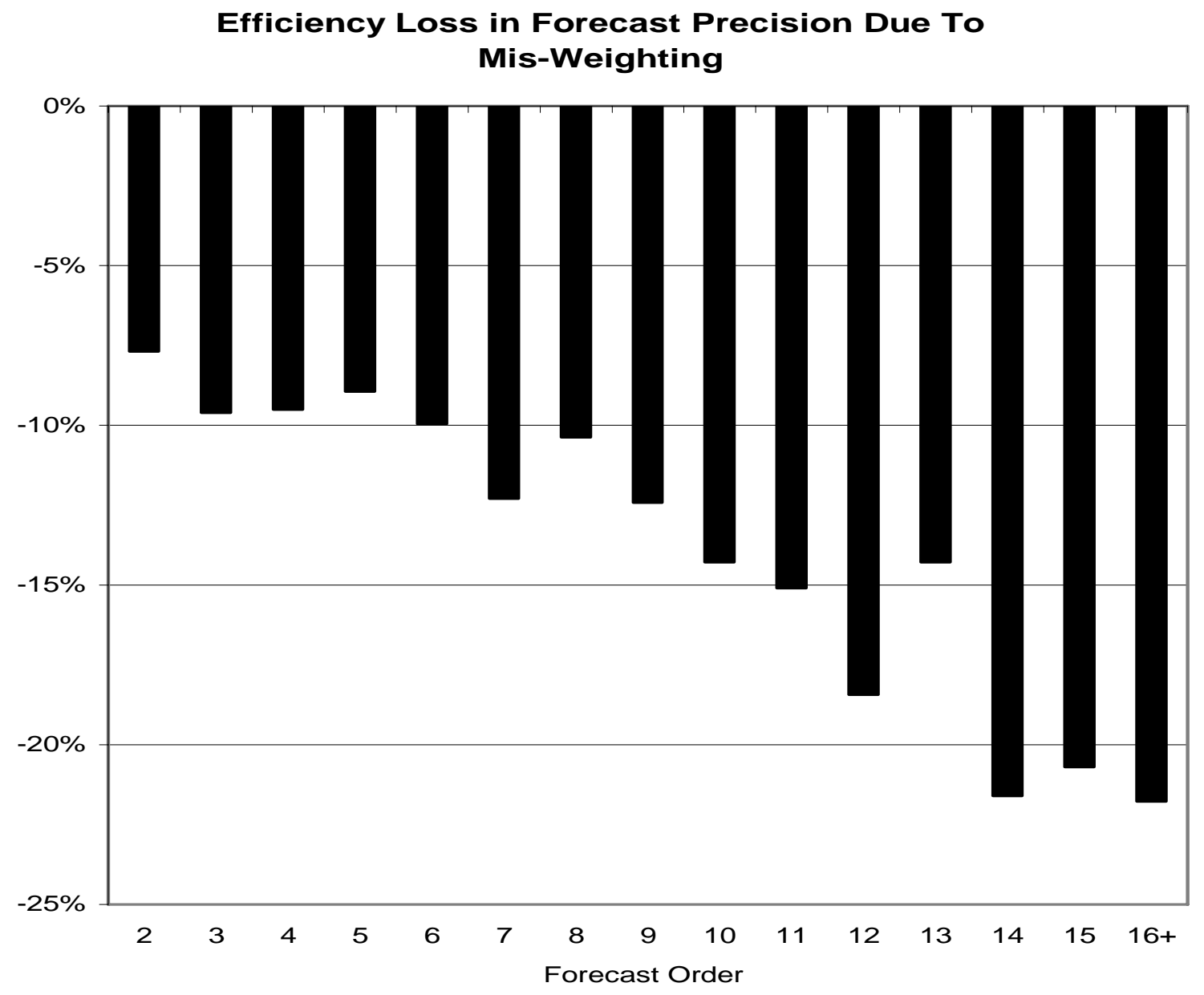

Difference in forecast precision

Figure 2: Efficiency Loss in Forecast Precision Due to Analyst Cognitive Biases

Figure expresses the percentage difference between the forecast precision of the current $\left(\mathrm{i}^{\text {th }}\right)$ analyst's actual forecast $F V_{t, t-1}^{1}$ and $F V_{t, t-1}^{3}$. The reported values are equal to the precision $F V_{t, t-1}^{1}$ divided by the precision of $F V_{t, t-1}^{3}$ minus one. The current $\left(\mathrm{i}^{\text {th }}\right)$ analyst's actual forecast is labeled $F V_{t, t-1}^{1} . F V_{t, t-1}^{3}$ is generated by regressing actual earnings on observable lagged forecasts, $F_{t, t-1}^{j} \mid \underset{j=1}{i-1}$, as well as the current $\left(\mathrm{i}^{\text {th }}\right)$ analyst's actual forecast. Forecasting parameters are reestimated each quarter, using all earnings data from previous quarters. Any difference in forecast precision between $F V_{t, t-1}^{1}$ and $F V_{t, t-1}^{3}$ is due to mis-weighting of information contained in the current and lagged forecasts. 


\section{Efficient Weights on Lagged Forecasts}

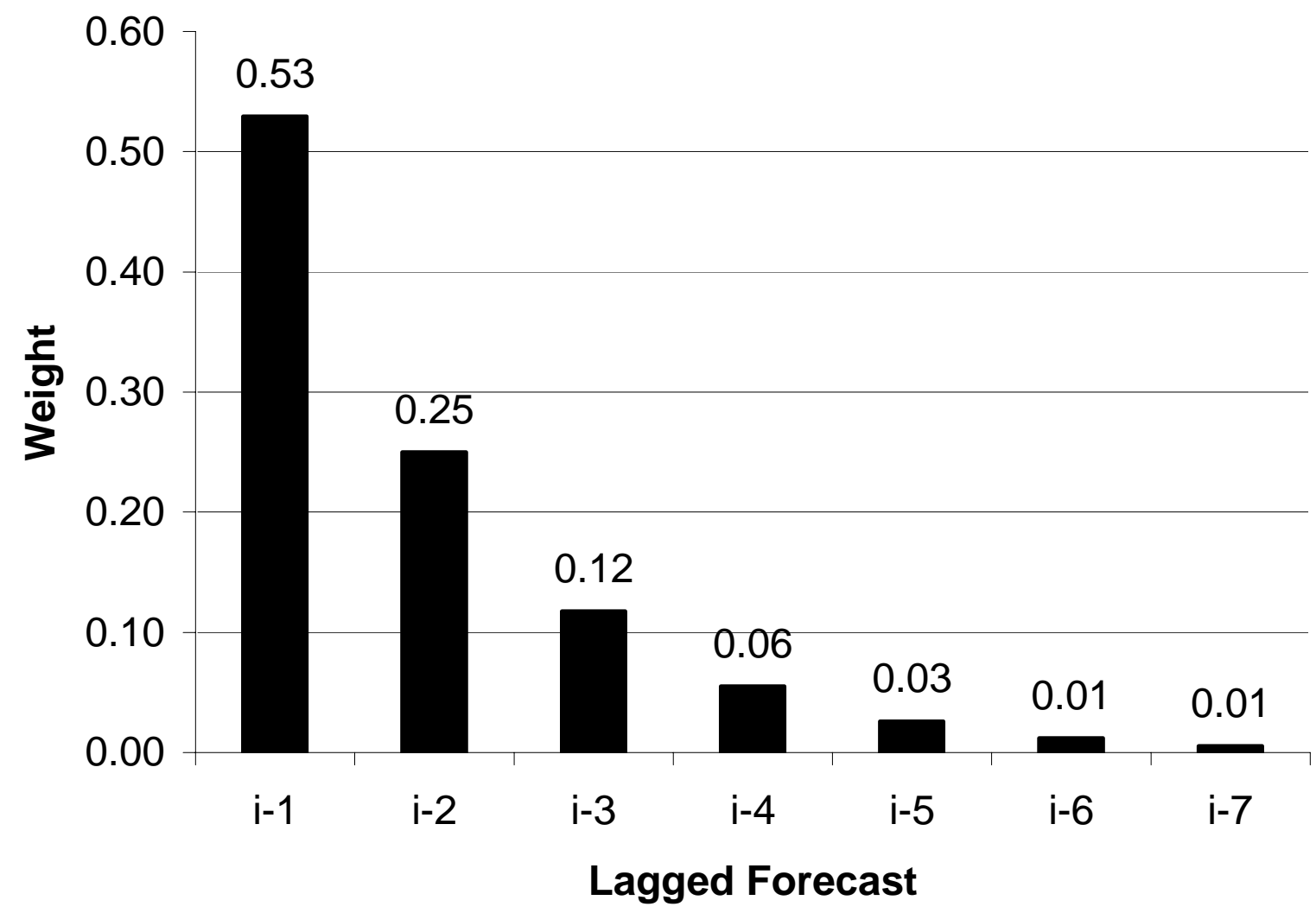

Figure 3. Consensus Forecast: Theoretical Weights on Lagged Forecasts.

The figure plots the efficient Bayesian weights placed on lagged forecasts to form an efficient consensus forecast. The actual weights on lagged forecasts are described in equation (11) in the text, and in general depend upon the precision of the initial information set, precision of past analyst private signals, and the degree of overconfidence exhibited by each past analyst. The weights above illustrate a special case with initial precision $\pi_{\varepsilon}=1.0$, constant private signal precision $\pi_{\eta}^{i}=0.10$ and constant overconfidence $(a=1)$. 


\section{Efficiency Loss in Forecast Precision Due To Analyst Cognitive Biases}

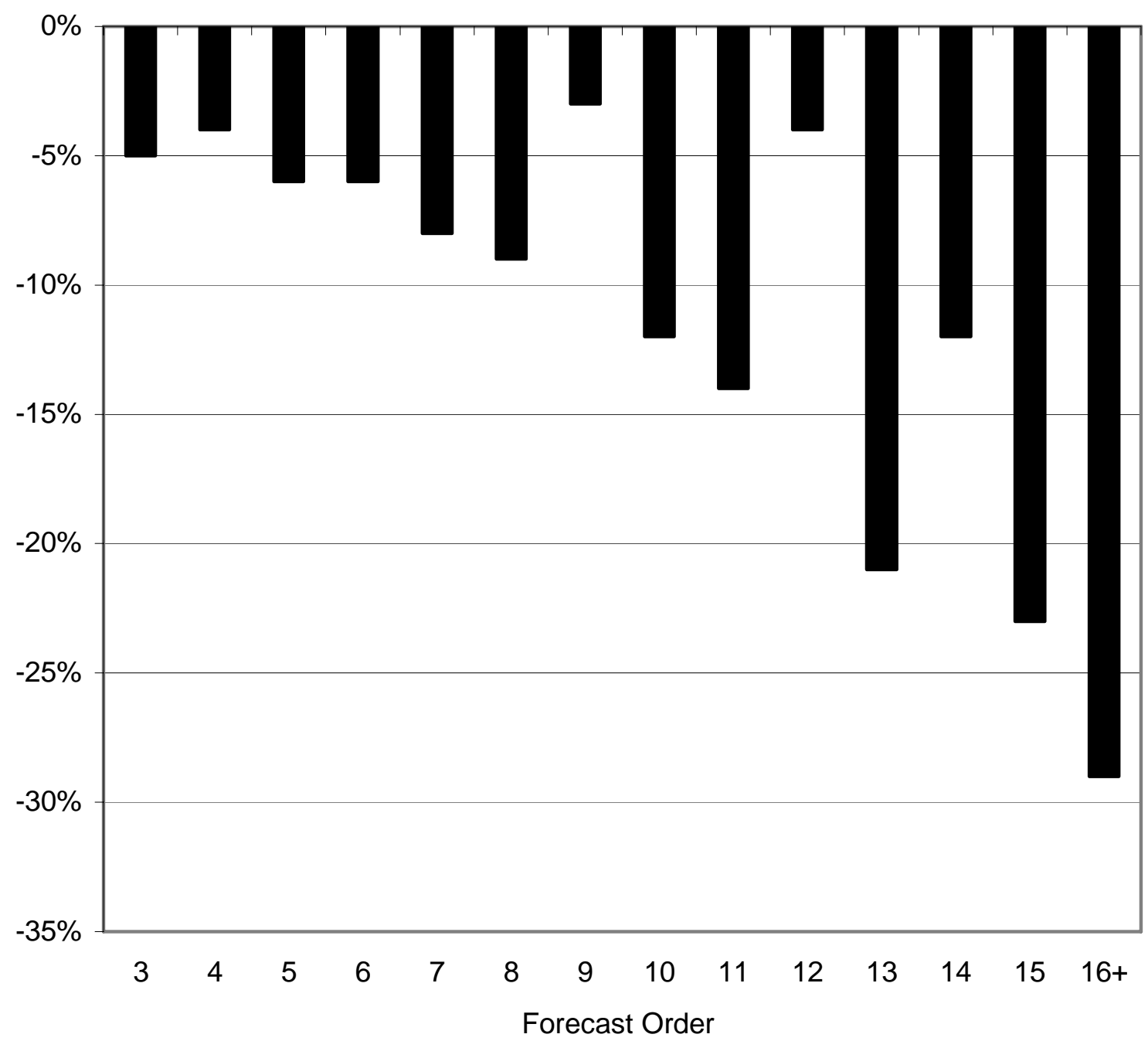

Actual current forecast (i) vs. efficient current forecast (i)

Figure 4: Efficiency Loss in Forecast Precision Due to Analyst Cognitive Biases

Figure expresses the percentage difference between the the current $\left(\mathrm{i}^{\text {th }}\right)$ analyst's actual forecast precision and the current $\left(i^{\text {th }}\right)$ efficient forecast. The $\left(i^{\text {th }}\right)$ efficient forecast is a weighted average of the current $\left(i^{\text {th }}\right)$ and past forecasts, with weights calculated according to equation (11) in the text. The difference between the efficient and actual forecast precisions represents the efficiency loss due to overconfidence and cognitive dissonance biases. Forecast precision is equal to the inverse sample mean-squared forecast error for each ordered forecast. The $i^{\text {th }}$ analyst could eliminate this efficiency loss by efficiently combining the $i^{\text {th }}$ private signal with the efficient consensus forecast. 